DANIEL SIMÕES DE JESUS

\title{
A INFLUÊNCIA DA PINEALECTOMIA NA FUNCIONALIDADE DAS CÉLULAS BETA PANCREÁTICAS
}

Dissertação apresentada ao Departamento de Fisiologia e Biofísica do Instituto de Ciências Biomédicas da Universidade de São Paulo, para obtenção do Título de Mestre em Ciências.

São Paulo

2011 
DANIEL SIMÕES DE JESUS

\title{
A INFLUÊNCIA DA PINEALECTOMIA NA FUNCIONALIDADE DAS CÉLULAS BETA PANCREÁTICAS
}

Dissertação apresentada ao Programa de Pós Graduação em Fisiologia Humana do Instituto de Ciências Biomédicas da Universidade de São Paulo, para obtenção do Título de Mestre em Ciências.

Área de Concentração: Fisiologia Humana

Orientador: Prof. Dr. Angelo Rafael Carpinelli

\author{
Versão corrigida
}

São Paulo

2011 
DADOS DE CATALOGAÇÃO NA PUBLICAÇÃO (CIP)

Serviço de Biblioteca e Informação Biomédica do

Instituto de Ciências Biomédicas da Universidade de São Paulo

reprodução não autorizada pelo autor

Jesus, Daniel Simões de.

A influência da pinealectomia na funcionalidade das células beta pancreáticas / Daniel Simões de Jesus. -- São Paulo, 2011.

Orientador: Angelo Rafael Carpinelli.

Dissertação (Mestrado) - Universidade de São Paulo. Instituto de Ciências Biomédicas. Departamento de Fisiologia e Biofísica. Área de concentração: Fisiologia Humana. Linha de pesquisa: Fisiologia da secreção de insulina.

Versão do título para o inglês: The influence of pinealectomy in pancreatic beta cell functionality.

Descritores: 1. Melatonina 2. Pinealectomia 3. Secreção de insulina 4. NAD(P)H oxidase 5. EROs I. Carpinelli, Angelo Rafael II. Universidade de São Paulo. Instituto de Ciências Biomédicas. Programa de Pós-Graduação em Fisiologia Humana III. Título. 
Título da Dissertação:

A influência da pinealectomia na funcionalidade das células beta pancreáticas.

Orientador(a):

Angelo Rafael Carpinelli.

A Comissão Julgadora dos trabalhos de Defesa da Dissertação de Mestrado, em sessão pública realizada a .I.
( ) Aprovado(a)
( ) Reprovado(a)

Examinador(a): Assinatura:

Nome:

Instituição:

Examinador(a): Assinatura:

Nome:

Instituição:

Presidente:

Assinatura:

Nome:

Instituição: 


\begin{tabular}{|c|c|}
\hline UNIVERSIDADE DE SÃO PAULO \\
INSTITUTO DE CIÊNCIAS BIOMÉDICAS \\
Cidade Universitária “Armando de Salles Oliveira" \\
Av. Prof. Lineu Prestes, 2415 - Cep. 05508-900 São Paulo, SP - Brasil \\
Telefone :(55) (011) 3091.7733 - telefax : (55) (011)3091-7438 \\
e-mail: cep@icb.usp.br \\
COMISSÃO DE ÉTICA EM EXPERIMENTAÇÃO ANIMAL
\end{tabular}

Decl. CEEA.032.09

\section{E C L A R A Ç Ã O}

Em adendo ao Certificado 65/09/CEEA datado de 02.06.09, por solicitação do Prof. Dr. Ângelo Rafael Carpinelli, responsável pela linha de Pesquisa, autorizo a inclusão do aluno Daniel Simões de Jesus ao projeto de pesquisa "Possível participação da enzima $N A D(P) H$ oxidase na modulação da função em célula $B$ pancreáticas em ratos pinealectomizados", uma vez que se trata de utilização da mesma espécie animal e de métodos experimentais similares ao referido certificado.

São Paulo, 01 de julho de 2009.

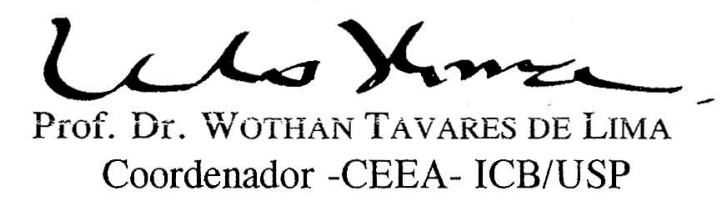




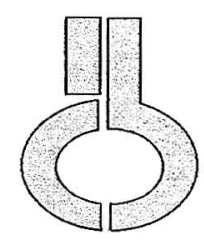

\section{UNIVERSIDADE DE SÃO PAULO INSTITUTO DE CIÊNCIAS BIOMÉDICAS}

Cidade Universitária "Armando de Salles Oliveira"

Av. Prof. Lineu Prestes, 2415 - CEP. 05508-000 São Paulo, SP - Brasil

Telefone :(55) (011) 3091.7733 - telefax : (55) (011) 3091.7438

e-mail: cep@icb.usp.br

\section{Certificado}

Certificamos que o protocolo registrado sob $n^{\circ} \mathbf{6 5}$ nas fls. 71 do livro 02 para uso de animais em experimentação, sob a responsabilidade do Prof(a) $\operatorname{Dr}(\mathrm{a})$ Ângelo Rafael Carpinelli, Coordenador(a) da Linha de pesquisa Possivel participação da enzima $\mathrm{NAD}(\mathrm{P}) \mathrm{H}$ oxidase na modulação da função em célula B pancreáticas em ratos pinealectomizados do qual participou(aram) o(s) alunos Eduardo R.L.de Oliveira, Laila r.B. dos Santos, Marco Taneda e o pesquisador José Cipolla Neto está de acordo com os Princípios Éticos de Experimentação Animal adotado pela Sociedade Brasileira de Ciência de Animais de Laboratório (SBCAL) e foi aprovado pela COMISSÃO DE ÉTICA EM EXPERIMENTAÇÃO ANIMAL (CEEA) em 02.06.09, com validade de 3 anos.

São Paulo, 10 de junho de 2009.

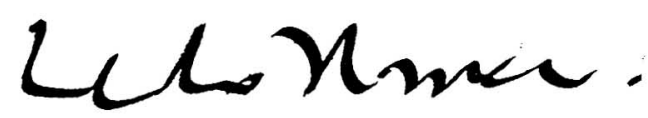

Prof.Dr.WOTHAN TAVARES DE LIMA Coordenador CEEA - ICB/USP

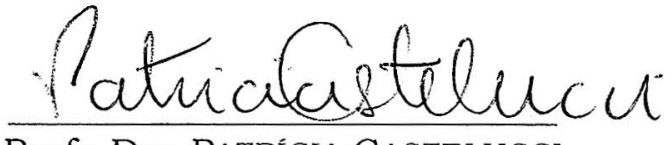

Profa.Dra.PATRICIA CASTELUCCI Secretäria CEEA - ICB/USP 
Aos meus pais, que me ensinaram que a educação e o respeito vem em primeiro lugar.

A minha irmã, pelas palavras de incentivo. 


\section{AGRADECIMENTOS}

Ao professor Angelo Rafael Carpinelli, que abriu as portas do seu laboratório e me deu uma grande oportunidade para meu crescimento profissional, além do pessoal, com seus conselhos sempre construtivos, tornando-se um grande amigo e por quem tenho muito respeito. $O$ bom baiano diz: Muito obrigado professor!

Aos meus pais, pelo imenso amor e estímulo que me dão em cada etapa da minha vida, pois sem dúvida nenhuma, se não fossem por vocês, jamais chegaria até aqui.

À minha irmã, Ananda, por toda amizade e cumplicidade. Te amo!

Aos amigos que fiz no laboratório de "Fisiologia da Secreção de Insulina", Fernanda, Maíra, Camila, Gabriela, Eloísa, Daniela, Laila e Eduardo. Aprendo muito com cada um de vocês. Obrigado por tudo!

À Marlene e Emiko, por sempre terem paciência comigo e por todo o carinho.

Ao professor José Cipolla por sanar todas as minhas duvidas e a todos de seu laboratório: Rodrigo, Rafael Peres, Rafael Previde, Ronaldo, Ana, Jéssica, Lia, Fernanda, Carol, Daniele, Marco e Julieta (Minha mãe loira). De uma coisa eu sei, também faço parte desse grupo, gosto muito de todos.

À professora Carla Roberta por me ajudar a pensar de maneira cientifica e a todos de seu laboratório: Mario, Felipe, Gabriela, Karina, Vitor, Nelo, Ricardo e Teca. Obrigado pela força! Relaxe Katherine, não esqueci de você, obrigado pela grande amizade.

Ao amigo Adílson e sua família, pela força, alegria e amizade, principalmente quando eu mais precisei. Você sempre será um grande amigo.

Ao Sidnei e Daniel, pela amizade e as conversas na hora do almoço.

Ao amigo Mauro, por todos os abraços e amizade.

Às amigas Aninha, Tatiane e Thaísa, pelo apoio em todos os momentos.

À todos do laboratório da professor Brito, obrigado pela amizade.

Aos amigos de departamento pela energia de todos os dias: Guga, Hilde, Aline, Leila, Sandra, Lucas, Camilo, Cris, Carlão, Gilly, Haroldo, Arnaldo, Leo, Cleitão, Emídio, Fran e André entre outros 
que por ventura eu tenha esquecido.

À Técnica Sandra do professor Fabio, pela paciência em me ensinar a utilizar o contador $\beta$.

Aos meus amigos de Salvador, pelo carinho e atenção, estando perto ou distante: Elaine Cristian, Edilton Junior, Jorge Jeferson e Carol.

À professora Maria Tereza Nunes, pelo carinho e amizade em todos os momentos.

À professora Andréa e Luciana Caperuto, pelos conselhos e amizade.

À todos os professores do Departamento de Fisiologia e Biofísica do ICB-I da USP, que direta ou indiretamente me auxiliaram frente às dificuldades científicas.

$\grave{A}$ todos da secretaria do departamento.

Aos funcionários do Biotério, Bob, Vilson, Maria Alice, Jaqueline, Miguel e Cláudio, sem o trabalho de vocês tudo seria mais difícil.

Aos funcionários da biblioteca, Delza, Socorro, Rosa, Jacinta, Renata, Mônica, Paulo, Edílson, e Yoshiyuki, Isabel, Juliana, Tereza, Eva por toda ajuda nos momentos de pesquisa e nos momentos de descontração, que são muitos.

Ao Valdeir, por tomar conta do ICB-I.

Ao Zé Maria e Itamar, pelos constantes auxílios, seja na pós-graduação ou no mundo da informática.

À Fapesp, CAPES e CNPq, pelo apoio Financeiro 
"Ainda que eu andasse pelo vale da sombra da morte, não temeria mal algum, porque tu estás comigo!" Salmo 21 


\section{RESUMO}

SIMÕES, D. A Influência da Pinealectomia na Funcionalidade das Células Beta Pancreáticas. 2011. 59 f. Dissertação (Mestrado em Fisiologia Humana) - Instituto de Ciências Biomédicas, Universidade de São Paulo, São Paulo, 2011.

As ilhotas pancreáticas têm em sua constituição as células $\beta$ pancreáticas, as quais têm como função secretar insulina, a qual é modulada pelas concentrações de nutrientes circulantes. A melatonina é secretada pela glândula pineal, estando envolvida em vários processos fisiológicos, como sono-vigília, homeostase da glicose, funções neuroendócrinas e ações antioxidantes. No entanto, a ausência da melatonina, por meio da pinealectomia (PINX), induz diversas alterações nas funções celulares, como a dessincronização do ritmo cicardiano do metabolismo da glicose e da secreção de insulina estimulada por nutrientes secretagogos. A $\mathrm{NAD}(\mathrm{P}) \mathrm{H}$ oxidase é um complexo enzimático constituído por seis subunidades, sendo $\left(\mathrm{p} 47^{\text {phox }}, \mathrm{p} 67^{\text {phox }}, \mathrm{p} 40^{\text {phox }}\right.$ e Rac) localizadas no citoplasma e duas na membrana celular $\left(\mathrm{p} 22^{\text {phox }}\right.$ e gp91 $\left.{ }^{\text {phox }}\right)$. A NAD(P)H oxidase é responsável pela produção de ânions superóxido através da redução do $\mathrm{NAD}(\mathrm{P}) \mathrm{H}$ e modula o metabolismo de glicose e a secreção de insulina estimulada pela glicose. Nosso estudo teve como objetivo avaliar uma possível modulação da NAD $(\mathrm{P}) \mathrm{H}$ oxidase pela PINX no Zeitgeber Time 6 e 18. Os resultados demonstram que a PINX induz alterações na funcionalidade das ilhotas pancreáticas, alterando a secreção de insulina estimulada pela glicose, o metabolismo da glicose, e o conteúdo de espécies reativas de oxigênio (EROs). Entretanto, não induz alterações nos respectivos ZTs, na expressão protéica das subunidades $\mathrm{p} 22^{\text {phox }}, \mathrm{p} 47^{\text {phox }}$ e gp91 ${ }^{\text {phox }}$. Demonstramos que a pinealectomia induz alteração no padrão rítmico metabólico e secretório nas ilhotas isoladas, tendo a $\mathrm{NAD}(\mathrm{P}) \mathrm{H}$ oxidase uma possível participação no desenvolvimento nas alterações observadas.

Palavras-chave: Secreção de insulina. Pinealectomia. Melatonina. NAD(P)H oxidase. EROs. 


\begin{abstract}
SIMÕES, D. The Influence of Pinealectomy in Beta Cell Functionality. 2011. 59 p. Masters thesis (Human Physiology) - Instituto de Ciências Biomédicas, Universidade de São Paulo, São Paulo, 2011.

Pancreatic islets are constituted by pancreatic $\beta$ cells, which main function is to secrete insulin, a hormone modulated by circulating nutrient concentrations. Melatonin is secreted by the pineal gland and is involved in several physiological processes as sleep-wake cycle, glucose homeostasis, neuroendocrine functions and antioxidant actions. However, the absence of melatonin by pinealectomy (PINX) induces several changes in cellular functions such as desynchronization of circadian rhythm of glucose metabolism and insulin secretion stimulated by glucose in pancreatic islets. The NAD $(\mathrm{P}) \mathrm{H}$ oxidase is an enzymatic complex composed by six subunits, and $\mathrm{p} 47^{\text {phox }}, \mathrm{p} 67^{\text {phox }}, \mathrm{p} 40^{\text {phox }}$ subunits and Rac are located in the cytoplasm and two components in the cell membrane (p22 $2^{\text {phox }}$ and gp91 ${ }^{\text {phox }}$ ). The NAD(P)H oxidase is responsible for producing superoxide through reduction of $\mathrm{NAD}(\mathrm{P}) \mathrm{H}$. It modulates the glucose metabolism and insulin secretion stimulated by glucose. Our study aimed to evaluate the possible modulation of $\mathrm{NAD}(\mathrm{P}) \mathrm{H}$ oxidase by pinealectomy in Zeitgeber Time 6:18. Our results show that the absence of melatonin induced by pinealectomy induces changes in the functionality of pancreatic islets, such as the insulin secretion stimulated by glucose, the glucose metabolism, and the content of reactive oxygen species (ROS). However, it does not induce changes in their respective $\mathrm{Zts}$ in the protein expression of the subunits $\mathrm{p} 22^{\text {phox }}, \mathrm{p} 47^{\text {phox }}$ and gp91 ${ }^{\text {phox }}$. We demonstrated that pinealectomy induces changes in metabolic and secretory rhythm pattern in isolated islets, being the NAD $(\mathrm{P}) \mathrm{H}$ oxidase a possibly responsible for the changes observed.
\end{abstract}

Key-Words: Insulin secretion. Pinealectomy. Melatonin. NAD(P)H oxidase. ROS. 


\section{LISTA DE FIGURAS}

Figura 1 - Esquema da via de sinalização da melatonina na célula $\boldsymbol{\beta}$ pancreática................24

Figura 2 - Estrutura da enzima NAD(P)H oxidase em seu estado basal e ativado............. 27

Figura 3 - Estrutura da família de enzimas NOX/DOUX .............................................. 29

Figura 4 - Efeito da glicose sobre o conteúdo intracelular de superóxido em animais controle e pinealectomizados .

Figura 5 - Análise do metabolismo da $\left[{ }^{14} \mathrm{C}\right]$-Glicose nos animais controle e

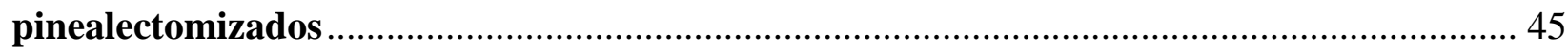

Figura 6 - Análise da secreção estática de insulina dos animais controle e pinealectomizados 48

Figura 7 - Expressão protéica das subunidades da NAD(P)H oxidase nos animais controle e pinealectomizados. 


\section{SUMÁRIO}

1 INTRODUÇÃO

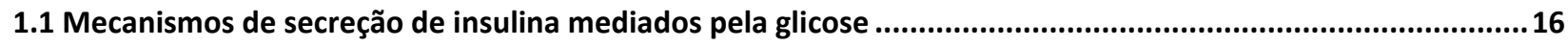

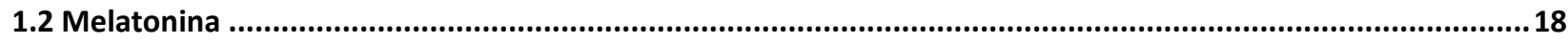

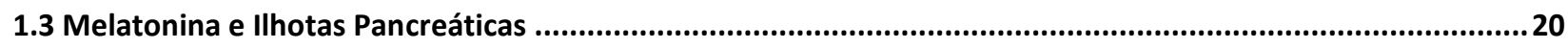

1.4 Pinealectomia e suas Implicações Fisiológicas no Metabolismo da Glicose ...............................................24

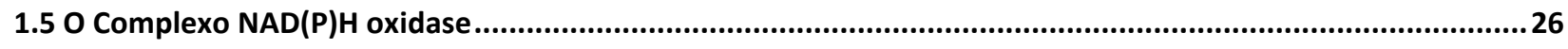

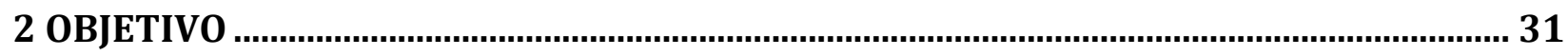

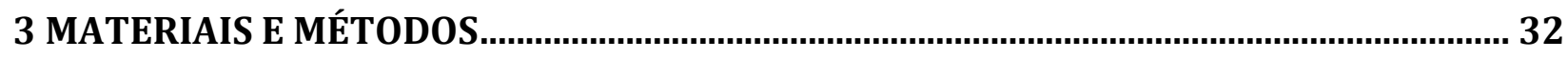

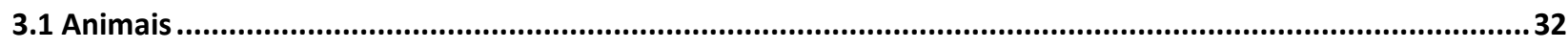

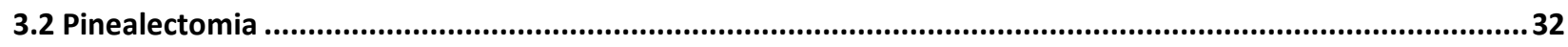

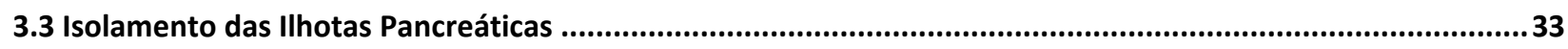

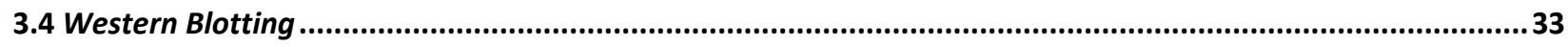

3.5 Análise do Conteúdo Intracelular das Espécies Reativas de Oxigênio ..................................................36

3.6 Análise da Secreção Estática de Insulina em Ilhotas Pancreáticas .....................................................36

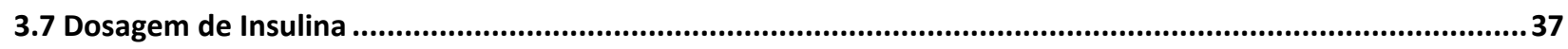

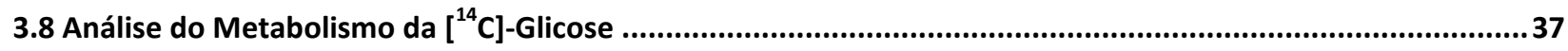

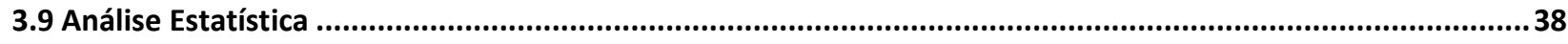

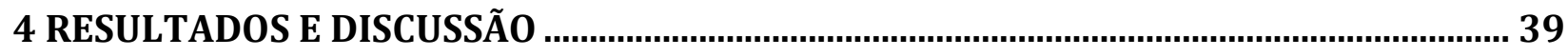

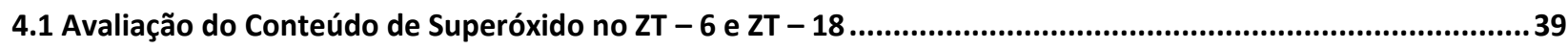




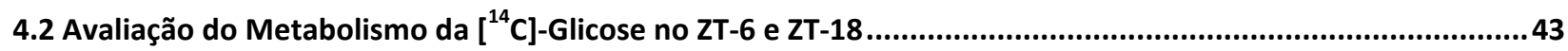

4.3 Avaliação da Secreção Estática de Insulina no ZT-6 e ZT-18 ...............................................................46

4.4 Avaliações da expressão protéica das subunidades da NAD(P)H oxidase no ZT-6 e ZT-18 ...........................49

5 CONCLUSÃO

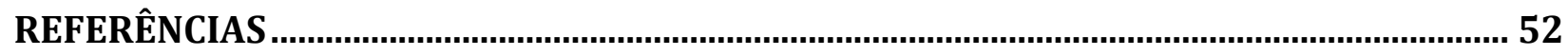




\section{INTRODUÇÃ̃O}

\subsection{Mecanismos de secreção de insulina mediados pela glicose}

O pâncreas endócrino é constituído por ilhotas pancreáticas, nas quais são identificadas quatro tipos de células: alfa $(\alpha)$, beta $(\beta)$, delta $(\delta)$ e PP, responsáveis pela secreção de hormônios peptídicos: glucagon, insulina, somatostatina e polipeptídeo pancreático respectivamente. No entanto, as ilhotas pancreáticas são constituídas principalmente por células $\beta(70-80 \%)$, secretoras de insulina, que é um hormônio polipeptídico responsável pela regulação da homeostase da glicose em diversos tecidos, como o muscular, adiposo e hepático. A insulina tem como principal secretagogo a glicose plasmática, entretanto, outros nutrientes também regulam a sua secreção, como ácidos graxos e aminoácidos.

A elevação da concentração de glicose plasmática aumenta o fluxo desse nutriente para o interior das células $\beta$ pancreáticas. $O$ transporte da glicose para o citosol é mediado pelo transportador de glicose do tipo 2 (GLUT-2), o qual possui um elevado Km (15 e $20 \mathrm{mM}$ ), e portanto, não saturável em concentrações fisiológicas de glicose (HABER et al., 2003). No meio intracelular, a glicose inicialmente é fosforilada a glicose- 6 fosfato pela atividade de duas enzimas: uma de baixa afinidade ( $\mathrm{Km} 6-11 \mathrm{mmol} / \mathrm{L})$ a hexoquinase IV ou glicoquinase e uma de alta afinidade $(\mathrm{Km}<0,1 \mathrm{mmol} / \mathrm{L})$ a hexoquinase $\mathrm{I}$, sendo a primeira fundamental para a regulação do fluxo glicolítico. Assim, a glicoquinase é tida como um sensor de glicose nas células $\beta$ pancreáticas (MATSCHINSKY, 1996).

O metabolismo da glicose na célula $\beta$ pancreática aumenta a razão ATP/ADP, que diminui a probabilidade de abertura dos canais $\mathrm{K}^{+}$sensíveis ao ATP $\left(\mathrm{K}_{\mathrm{ATP}}\right)$, diminuindo o efluxo de $\mathrm{K}^{+}$, resultando no aumento do potencial elétrico da membrana plasmática. $\mathrm{O}$ aumento de potencial de membrana aumenta a probabilidade de abertura dos canais para $\mathrm{Ca}^{+2}$ sensíveis à voltagem (CCSV ou do tipo - L) elevando a entrada íon $\left(\left[\mathrm{Ca}^{+2}\right]_{\mathrm{i}}\right)$, com subsequente ativação da maquinaria secretória da célula $\beta$ e exocitose dos grânulos insulínicos (GILON e HENQUIN, 2001; HABER et al., 2003). A resposta fisiológica da secreção de insulina é altamente dependente da oscilação da [Ca $\left.{ }^{+2}\right]$ (GEMBAL; GILON; HENQUIN, 1992). 
Enzimas associadas à membrana plasmática, como as isoformas da fosfolipase C (PLC), a fosfolipase $\mathrm{A}_{2}$ (PLA2), a fosfolipase $\mathrm{D}$ e a adenilato ciclase desempenham papel importante na regulação do processo secretório de insulina. A ativação dessas enzimas é mediada pela ligação de hormônios e neurotransmissores a receptores de membrana e/ou pelas variações da concentração do $\left[\mathrm{Ca}^{+2}\right]_{\mathrm{i}}$, resultando na formação de segundos mensageiros intracelulares que modulam a exocitose dos grânulos insulínicos.

Assim, a ativação das isoformas da PLC resulta na hidrólise de fosfolipídios de membrana, resultando na formação de 1,4,5 inositol-trifosfato (IP3), e diacilglicerol (DAG). O $\mathrm{IP}_{3}$ promove a abertura dos canais de cálcio $\left(\mathrm{Ca}^{+2}\right)$, localizados na membrana do retículo endoplasmático, desencadeando o efluxo de $\mathrm{Ca}^{+2}$ do interior da organela para o citoplasma e aumentando a concentração deste íon no citosol. O DAG permanece na membrana e, juntamente com o íon $\mathrm{Ca}^{+2}$, ativa diversas isoformas de proteína quinase C (PKC) (JONES; PERSAUD; HOWELL, 1992; HABER et al., 2003). A PKC promove a fosforilação e ativação das proteínas do citoesqueleto que participam da translocação dos grânulos de insulina para a membrana plasmática, favorecendo a exocitose de insulina (NESHER et al., 2002).

A secreção de insulina estimulada pela glicose pode ser potencializada por mecanismos independentes dos $\mathrm{K}_{\mathrm{ATP}}$, quando os mesmos já se encontram funcionalmente bloqueados, sendo estes mecanismos caracterizados como a via de amplificação da secreção de insulina. A ativação da enzima adenilato ciclase resulta no aumento intracelular de adenosina monofosfato cíclico $\left(\mathrm{AMP}_{\mathrm{C}}\right)$, segundo mensageiro ativador da proteína quinase $\mathrm{A}(\mathrm{PKA})$, a qual também contribui para a exocitose dos grânulos de insulina. Além disso, a PKA modula os canais para $\mathrm{Ca}^{+2}$ sensíveis à voltagem e $\mathrm{K}_{\mathrm{ATPs}}$, sendo um importante fenômeno amplificador da secreção de insulina estimulada pela glicose (THAMS; ANWAR; CAPITO, 2005).

Nosso grupo demonstrou recentemente que as espécies reativas de oxigênio (EROs) também possuem um papel modulador importante no processo de secreção de insulina, sendo regulada por glicose, ácidos graxo, citocinas (MORGAN et al., 2007; MORGAN et al., 2009; GRACIANO et al., 2010). Estudos recentes demonstram que a melatonina também atua como modulador do processo secretório deste hormônio (PICINATO et al., 2002b). 


\subsection{Melatonina}

A melatonina (N-acetil-5-metoxitriptamina) é uma indolamina de peso molecular 232,3 g/mol, sintetizada a partir do aminoácido essencial triptofano que é transformado em 5hidroxitriptofano pela triptofano hidroxilase 1 (TPH1), este passa por uma descarboxilação subsequente catalisada pela descarboxilase de 1 aminoácidos aromáticos que resulta na formação de seretonina. A serotonina é, por sua vez, acetilada pela ação da arilalquilimina Nacetiltranferase (AANAT) e transformada em $\mathrm{N}$-acetilserotonina, que tem o grupamento hidroxila trocado por metil pela ação da hidroxindol-oxi-metiltransferase (HIOMT), culminando na formação de melatonina (CIPOLLA-NETO et al., 1999).

O sistema neural que controla a síntese da melatonina pela glândula pineal origina-se no núcleo paraventricular do hipotálamo que se projeta para coluna intermédio-lateral da medula torácica alta, nos neurônios pré-ganglionares do sistema nervoso autônomo simpático. Estes neurônios projetam-se, então, para os gânglios cervicais superiores, cujos neurônios pósganglionares se projetam para a glândula pineal através dos ramos carotídeos internos e nervos coronários. (CIPOLLA-NETO e AFECHE, 2007).

A melatonina é produzida e secretada pelos pinealócitos na glândula pineal em um ritmo cicardiano, agindo como um transdutor neuroendócrino de informações sobre o fotoperíodo sazonal e cicardiano. Em mamíferos, está envolvida em vários processos fisiológicos conferindo ritmicidade a uma série de funções neuroendócrinas, modulando o ciclo sono-vigília, a atividade reprodutora e a atividade metabólica.

Conferido pela sua estrutura química, a melatonina apresenta uma característica de anfifilicidade, promovida pela presença dos grupamentos metoxi no carbono 5 e do grupamento acil ligado ao nitrogênio do grupo amina. Ou seja, ela tem propriedade de difundir-se com igual capacidade tanto em meios hidrofílicos quantos lipofílicos. (CIPOLLA-NETO e AFECHE, 2007) Possuindo essa característica, a melatonina pode exercer suas ações pela interação a receptores de membrana, receptores nucleares (SMIRNOV, 2001; SLOMINSKI et al., 2008) e pela interação direta com moléculas no citoplasma (SLOMINSKI et al., 2008). Além disso, a melatonina apresenta importante ação antioxidante, protegendo as células de danos causados por espécies reativas de oxigênio e nitrogênio, no metabolismo oxidativo e no transporte de elétrons pela sua 
ação intra-mitocondrial (LOPEZ et al., 2009).

Os receptores para melatonina localizados na membrana plasmática foram identificados em estruturas neuronais e não-neuronais (MORGAN et al., 1994), e classificados de acordo com as diferenças farmacológicas de ligação ao análogo radioativo 2-[ $\left.\mathrm{I}^{125}\right]$-iodomelatonina. Nos mamíferos, estão bem caracterizados três tipos de receptores de membrana para melatonina (DUBOCOVICH, 1995). Inicialmente, foram descritos os receptores do tipo $\mathrm{MT}_{1}$ e $\mathrm{MT}_{2}$. Os receptores de melatonina pertencem à superfamília de receptores acoplados à proteína $\mathrm{G}$, e isso implica na modulação de mecanismos de transdução intracelular.

$\mathrm{O}$ receptor $\mathrm{MT}_{1}$ possui uma interação com o componente inibitório da proteína $\mathrm{G}$, a subunidade $\alpha_{\mathrm{i}}$ (inibição da adenilato ciclase). O componente $\mathrm{G} \alpha_{\mathrm{i}}$, sendo sensível à toxina pertussis, promove uma redução na produção de AMPc e consequente diminuição da ativação da PKA (MORGAN et al., 1995), com redução da fosforilação de proteínas alvo, incluindo o elemento de ligação a proteínas responsivo ao AMPc (CREB). O receptor $\mathrm{MT}_{1}$ e o receptor $\mathrm{MT}_{2}$ interagem com o componente $\beta \gamma$ da proteína Gq11 (ativação da fosfolipase C). O componente Gq11 permite a hidrólise de fosfolipídios de membrana, resultando na formação de $\mathrm{DAG} \mathrm{e} \mathrm{IP}_{3}$, resultando no aumento da concentração intracelular de $\mathrm{Ca}^{+2}$ oriundo do retículo endoplasmático e ativação da PKC, respectivamente (BARRETT et al., 1996). Ademais, o receptor $\mathrm{MT}_{2}$ também reduz a concentração de AMPc através do componente inibitório da proteína $\mathrm{G}$, a subunidade $\alpha_{\mathrm{i}}$, no entanto, a inibição da formação de GMPc com consequente redução da ativação da proteína quinase $\mathrm{G}(\mathrm{PKG})$ é a principal característica desse receptor (HARDELAND, 2009).

A melatonina é conhecida também por exercer controle sobre o estado redox celular através da modulação de centros formadores de espécies reativas de oxigênio e nitrogênio, inibindo enzimas pró-oxidantes, como a expressão da isoforma induzível da sintase de óxido nítrico (iNOS) (ALONSO; COLLADO; GONZALEZ-GALLEGO, 2006) e a NAD(P)H oxidase (ZHOU et al., 2008), além de aumentar a expressão de enzimas antioxidantes em diversos tecidos sob estresse oxidativo (REITER et al., 2000a). Ozturk et al. (2000) encontraram aumento da atividade da superóxido dismutase (SOD) no fígado de ratos após a administração de $10 \mathrm{mg} / \mathrm{kg}$ de melatonina durante 7 dias (OZTURK et al., 2000), enquanto Liu et al. (2000) reportaram aumento da atividade da SOD nos rins, fígado e cérebro de ratos após uma única administração de $5 \mathrm{mg} / \mathrm{kg}$ da indolamina (LIU e NG, 2000). A melatonina também é capaz de aumentar a 
expressão da glutationa total (tGSH), reduzir a concentração da glutationa oxidada (GSSG) com subsequente aumento na atividade da glutationa peroxidase (GSH-Px), indicando que a melatonina pode agir em vários pontos do sistema de defesa antioxidante (RODRIGUEZ et al., 2004; CARRETERO et al., 2009).

Considerando que a melatonina possui uma característica de anfifilicidade, ela atravessa a membrana plasmática e exerce uma ação direta antioxidante de EROs. Dentre as EROs estão o ânion superóxido, peróxido de hidrogênio, radical hidroxila e espécies reativas de nitrogênio, como o óxido nítrico e o peroxinitrito (REITER, 1997; KUCUKAKIN; GOGENUR; ROSENBERG, 2007). Além disso, esta indolamina promove melhora na atividade dos complexos I, III e IV da cadeia de transporte de elétrons na mitocôndria, aumentando a eficiência da fosforilação oxidativa, além de reduzir o potencial de membrana mitocondrial interno, com subsequente redução no consumo de oxigênio e produção de EROs (LOPEZ et al., 2009).

\subsection{Melatonina e Ilhotas Pancreáticas}

A relação entre a glândula pineal e ilhotas pancreáticas modulando o metabolismo dos carboidratos vem sendo questionada há décadas. As informações sobre o metabolismo da glicose e a secreção de insulina pelas ilhotas pancreáticas sendo moduladas pela melatonina são muito contraditórias. Estudos mostram que a melatonina reduz a secreção de insulina induzida pela glicose em ratos e camundongos, sem alteração da secreção basal de insulina (Atkins et al., 1973). Entretanto, Bailey et al. (1974) mostraram que a infusão crônica de melatonina exerce pouco efeito na redução da secreção de insulina e na sua concentração plasmática (BAILEY; ATKINS; MATTY, 1974). Além disso, altas concentrações de melatonina em animais cegos (BENSON; MILLER; SORRENTINO, 1971) ou aplicações de melatonina exógena (BURNS, 1973) aumentam a concentração de glicose no sangue, enquanto (CSABA e NAGY, 1973) observaram redução da glicemia e (NANU-IONESCU e IONESCU, 1969; QUAY e GORRAY, 1980) elevação da insulinemia, sendo essas observações induzida possivelmente pela pinealectomia.

Diversos autores concluíram que a glândula pineal exerce um efeito supressor na atividade da célula $\beta$ pancreática, porque a melatonina reduz a concentração de insulina em ratos (RASMUSSEN et al., 1999; RASMUSSEN et al., 2001), sendo esses efeitos condizentes com a 
redução da tolerância a glicose (DHAR et al., 1983). O aumento da concentração de insulina exerce efeito inibitório sobre a glândula pineal (CHAMPNEY et al., 1985) ao mesmo tempo que altera a sensibilidade temporal na glândula pineal de ratos in vitro, potencializando a ação da noradrenalina na síntese de melatonina (PELICIARI-GARCIA et al., 2010) Esses dados mostram que a interação das ações da melatonina com as da insulina são complexas tanto no pâncreas quanto na glândula pineal. Essas questões permanecem até o presente momento sem esclarecimento definitivo, embora publicações recentes venham tentando esclarecer como a melatonina regula o metabolismo dos carboidratos e a secreção de insulina pelas células $\beta$ pancreáticas.

Para melhor entender as contradições em relação às ações da melatonina sobre a secreção de insulina pelas células $\beta$ pancreáticas, diversos estudos com ilhotas pancreáticas isoladas foram realizados. Peschke et al. (1997) utilizando um sistema de perfusão ${ }^{1}$ observaram que ilhotas pancreáticas isoladas tratadas somente com melatonina ou serotonina, não influenciavam na secreção basal de insulina, entretanto, quando era adicionado glicose ou cloreto de potássio (KCL), foram obtidas respostas distintas. Em estímulos com glicose ou KCL e melatonina, houve redução da secreção de insulina, sendo que, com serotonina ocorreu aumento da secreção do hormônio (PESCHKE et al., 1997). Assim, ficou claro que a melatonina interfere na secreção de insulina, entretanto, ainda era desconhecida a via pela qual ocorre esse fenômeno.

Em estudos posteriores, ficou caracterizado que a secreção de insulina, além de ser modulada pela melatonina, apresenta um ritmo cicardiano. Foi observado inicialmente que essa indolamina reduz a secreção de insulina, mas induz um avanço de fase de nove horas, com manutenção do ritmo cicardiano e aumento da amplitude da liberação do hormônio (PESCHKE e PESCHKE, 1998). A ritmicidade cicardiana da secreção de insulina pela melatonina, pode ser mediada pela regulação da expressão dos clock genes, uma vez que a função desses é controlar a transcrição de outros genes denominados genericamente por "genes controlados pelo relógio". Sabe-se que as ilhotas pancreáticas expressam os clock genes (MUHLBAUER et al., 2004) e a ausência dos mesmos reduz a secreção de insulina (MARCHEVA et al., 2010). Dellatre et al. (1999) mostraram a ritmicidade cicardiana da intensidade de resposta das ilhotas pancreáticas de ratos, frente a uma estimulação glicêmica. Observaram também que no inicio do período noturno,

\footnotetext{
${ }^{1}$ Ver revisão de (CSERNUS et al., 1998).
} 
as ilhotas isoladas apresentaram uma maior capacidade secretória frente ao mesmo estímulo de glicose. Essas e outras informações deixam claro que o tecido pancreático endócrino, apresenta um processo rítmico adaptativo ao período de maior atividade e consumo alimentar (DELATTRE; CIPOLLA-NETO; BOSCHERO, 1999), além de manter, in vitro, a memória do horário de retirada do alimento.

Peschke et al. (2000) observaram em ilhotas pancreáticas de ratos neonatos, que a melatonina reduz a secreção de insulina estimulada por forskolin, sendo esse fenômeno mediado pelo receptor $\mathrm{MT}_{1}$ que reduz a concentração intracelular de AMPc (PESCHKE et al., 2000; KEMP; UBEDA; HABENER, 2002). Em estudo posterior, o mesmo grupo mostrou que a melatonina também inibe a secreção de insulina em células $\beta$ primárias (PESCHKE et al., 2002). Dentro desse contesto, Picinato et al. (2002) mostraram que a melatonina reduz a secreção de insulina por ilhotas isoladas de animais adultos embora não interfira na metabolização da glicose pelas ilhotas, mas reduza a expressão da PKA, sem alterar a expressão da PKC (PICINATO et al., 2002b) (Figura 1).

Por outro lado, ratos tratados com alta dose de melatonina (1 mg/kg) apresentam aumento na concentração plasmática de insulina e de glicose. Além disso, pâncreas de rato perfundidos com melatonina (100 nM) mostraram oscilações da secreção de insulina (FABIS; PRUSZYNSKA; MACKOWIAK, 2002). Assim, aparentemente as ações da melatonina sobre as ilhotas pancreáticas in vivo, in vitro e in situ são bastante distintas.

Bach et al. (2005) ressaltam que a melatonina, além de modular a concentração intracelular do AMPc mediada pelo receptor $\mathrm{MT}_{1}$, regula a concentração intracelular do $\mathrm{Ca}^{+2}$ e do $\mathrm{IP}_{3}$ em células $\beta$ primárias, indicando outra via de sinalização mediada por receptores de membrana (BACH et al., 2005). Considerando que a concentração intracelular do $\mathrm{Ca}^{+2}$ é essencial para a secreção de insulina, a ação da melatonina modulando a funcionalidade das ilhotas pancreáticas ou células $\beta$ primárias, ainda permanece desconhecida. No entanto, em estudos posteriores, Peschke et al. (2006) mostraram que a melatonina modula diferentes vias de sinalização nas células $\beta$ pancreáticas, inibindo e/ou estimulando a secreção de insulina (PESCHKE; BACH; MUHLBAUER, 2006).

As ilhotas pancreáticas também expressam o receptor $\mathrm{MT}_{2}$, o qual é conhecido por modular a concentração de GMPc, porém, a expressão desse receptor é consideravelmente menor 
comparado à do $\mathrm{MT}_{1}$ (MUHLBAUER e PESCHKE, 2007). Foi demonstrado que a ação da melatonina, mediada pelo receptor $\mathrm{MT}_{2}$ em células $\beta$ primárias, reduz a secreção de insulina concomitante à redução da concentração intracelular do GMPc (STUMPF; MUHLBAUER; PESCHKE, 2008; STUMPF; BAZWINSKY; PESCHKE, 2009), detalhando outro via pela qual a melatonina modula a funcionalidade das células $\beta$ pancreáticas.

Ramracheya et al. (2008) revelaram que ilhotas pancreáticas humanas expressam os receptores de melatonina, entretanto, diferente dos resultados encontrados nas ilhotas isoladas de ratos, esta indolamina estimulou a secreção de insulina (RAMRACHEYA et al., 2008). A incubação das ilhotas humanas com melatonina estimula as células $\alpha$ pancreáticas a secretar glucagon, que incita as células $\beta$ pancreáticas a secretar insulina. Essa ação foi confirmada pelo recente trabalho de Bãhr et al. (2011), que mostraram que as células $\alpha$ pancreáticas expressam os receptores de melatonina e que estes estimulam a secreção do glucagon (BAHR et al., 2011).

Adicionalmente, outras ações da melatonina através do receptor $\mathrm{MT}_{1}$ englobam a interação com as vias de sinalização do receptor de insulina e do receptor do fator de crescimento semelhante a insulina, aumentando a fosforilação em tirosina desses receptores e das proteínas Akt, ERK1/2, pSTAT3 em ilhotas pancreáticas isoladas (PICINATO et al., 2008), mostrando uma via alternativa de ação da melatonina. Através dessas vias a indolamina pode influenciar no crescimento e desenvolvimento da ilhota. Entretanto, a ausência da melatonina, secundaria à pinealectomia, induz ao aumento da área, menor densidade celular e maior intensidade dos processos patológicos degenerativos nas ilhotas pancreáticas (Lima et al., 2001).

A melatonina é um hormônio antioxidante e exerce ações diretas sobre as espécies reativas de oxigênio (EROs), também modulando a expressão de enzimas antioxidantes (REITER et al., 2008). Assim, considerando que as ilhotas pancreáticas possuem uma concentração reduzida de enzimas antioxidantes com vulnerabilidade a estresse oxidativo (LENZEN; DRINKGERN; TIEDGE, 1996; LENZEN, 2008), a melatonina parece exercer uma ação antioxidante importante no controle de EROs em ilhotas pancreáticas (EBELT et al., 2000). 


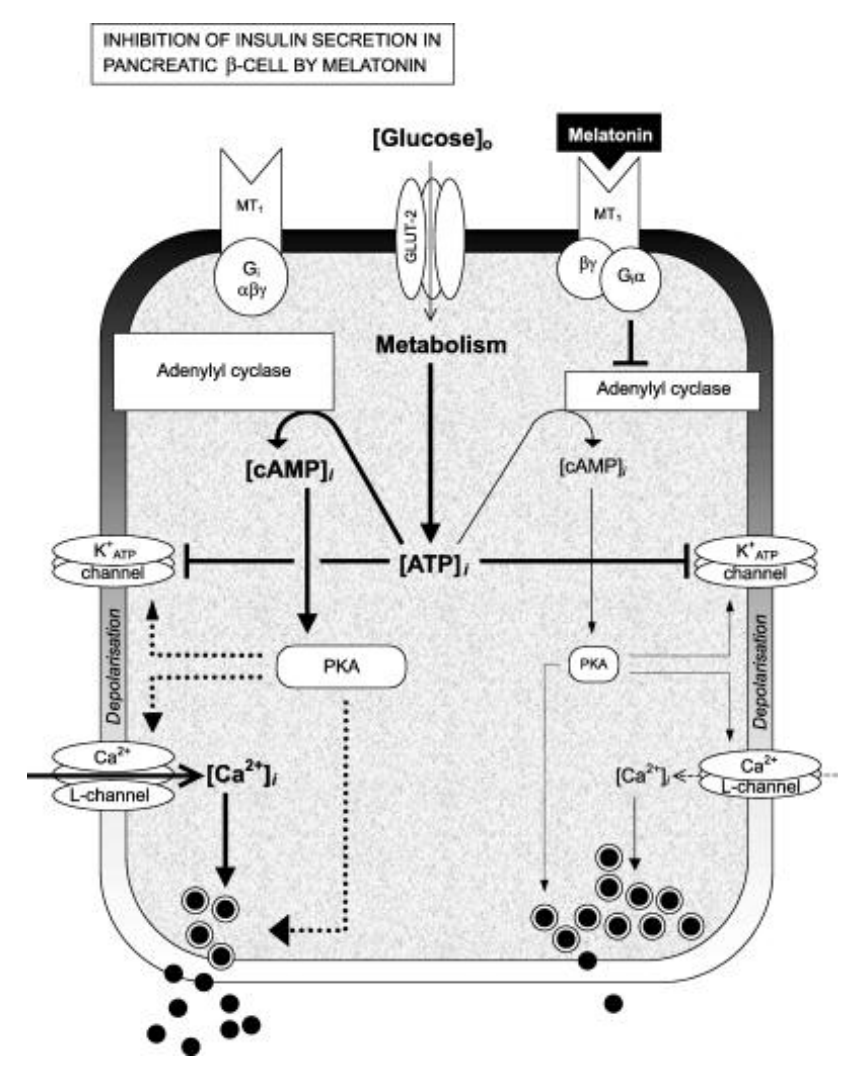

Figura 1 - Esquema da via de sinalização da melatonina na célula $\beta$ pancreática. Ação da melatonina no receptor MT1, mediando uma redução na concentração de AMPc e concomitante redução da secreção de insulina.

FONTE: (PESCHKE et al., 2002).

\subsection{Pinealectomia e suas Implicações Fisiológicas no Metabolismo da Glicose}

Para um melhor entendimento dos efeitos da melatonina sobre os processos fisiológicos, o uso de animais pinealectomizados tornou-se um modelo experimental interessante e muito utilizado.

Os estudos utilizando animais pinealectomizados para melhor entender as ações da melatonina na regulação do metabolismo da glicose começaram no século XX, mais precisamente na década de 70 , avaliando se a pinealectomia alterava a concentração da glicose plasmática em ratos diabéticos induzidos por aloxana. Nesse estudo, não foi observada a diferença na glicemia entre o grupo pinealectomizado e controle após o tratamento (GORRAY e QUAY, 1978). Por outro lado, no estudo seguinte, o mesmo grupo observou que a pinealectomia alterou a secreção de insulina. As ilhotas isoladas de ratos pinealectomizados, somado a uma 
mistura de extratos da pineal com córtex cerebral no meio de cultura, induziu uma hipersecreção de insulina (GORRAY; QUAY; EWART, 1979).

Diaz et al. (1986) observaram que a ausência da pineal reduz a concentração plasmática de insulina, concomitante ao aumento na concentração de glucagon e aparente intolerância à glicose (DIAZ e BLAZQUEZ, 1986), estudo que foi corroborado por (RODRIGUEZ et al., 1989). Além disso, a ausência da melatonina modificou o ritmo diário da concentração plasmática de glicose (MURLIDHAR et al., 1991), demonstrando a importância da pineal na fisiologia da secreção de insulina.

Lima et al. (1998) observaram que a pinealectomia induz a resistência insulínica, não devido a uma alteração na sua via de sinalização, mas pela redução da quantidade de transportadores de glicose 4 (GLUT 4) nas células do tecido adiposo e muscular. In vivo, a pinealectomia induziu uma dessincronização cicardiana dos eventos metabólicos, com redução da capacidade de resposta a uma elevada concentração de glicose, de acordo com a hora do dia. Ademais, a pinealectomia também modificou a ritmicidade da secreção de insulina induzida por altas concentrações de glicose, havendo redução da concentração plasmática de insulina no fim do período diurno (LIMA et al., 1998). La Fleur et al. (2001) mostraram a importância da melatonina sobre o metabolismo de carboidratos e a manutenção glicêmica, observando que a ausência da pineal induz hiperglicemia noturna (LA FLEUR et al., 2001). A hipótese de que a ausência da glândula pineal induz a uma dessincronização rítmica metabólica, levando os animais a desenvolverem resistência a insulina, foi corroborada por Contreas-Alcantera et al. (2010) que demonstraram que animais Knockout para o receptor $\mathrm{MT}_{1}$ tornam-se incapazes de metabolizar a glicose adequadamente, provavelmente pelo desenvolvimento da resistência a insulina (CONTRERAS-ALCANTARA; BABA; TOSINI, 2010).

Nosso grupo, em colaboração ao grupo de pesquisa do Prof. Dr. José Cipolla, descreveu esse mesmo efeito de desorganização rítmica metabólica provocada pela pinealectomia, quando se considera a capacidade das ilhotas pancreáticas isoladas de responderem à um estimulo de glicose. Foi também observado que o ajuste rítmico metabólico e secretório está, de fato, na dependência diária de melatonina, uma vez que ilhotas pancreáticas isoladas de animais pinealectomizados apresentam um adiantamento de fase de quase 3 horas da curva diária da secreção de insulina estimulada por glicose (PICINATO et al., 2002a). Isso fez com que seu pico de máxima responsividade seja durante o dia, e não à noite, quando seria funcionalmente 
necessário por ser o período cicardiano em que os animais se alimentam.

Em estudos posteriores, Borges-Silva et al. (2007) observaram que a pinealectomia reduz o conteúdo de glicogênio muscular e hepático, além de não apresentar melhora da capacidade aeróbia induzida pelo treinamento (BORGES-SILVA et al., 2007). Nogueira et al. (2011) mostraram que a ausência da melatonina promove resistência à insulina no tecido hepático durante o período noturno com aumento da gliconeogênese mediada pelo aumento da atividade e da expressão da fosfoenolpiruvato carboxiquinase (PEPCK) (NOGUEIRA et al., 2011). Esses dados mostram uma participação importante da melatonina na regulação do metabolismo hepático da glicose, sendo que, a ausência do referido indol aumenta a produção da glicose no período noturno induzido pela redução do conteúdo de glicogênio hepático e muscular (LA FLEUR et al., 2001; BORGES-SILVA et al., 2007).

A melatonina exerce um controle na expressão e atividade de diversas enzimas antioxidantes (REITER et al., 2000b). Assim, a homeostase do estado redox no meio intracelular encontra-se alterada no animal pinealectomizado, observando aumento da peroxidação de lipídeos e consequente redução da atividade de algumas enzimas antioxidantes como a glutationa peroxidase e catalase. Tanto no período diurno quanto noturno a pinealectomia induz a redução da atividade das enzimas antioxidantes, favorecendo um aumento da concentração de EROs e posterior dano celular pela deficiência do sistema antioxidante (BAYDAS et al., 2002). A reposição de melatonina nos animais pinealectomizados reverte parcialmente os danos mediados pelas EROs (SAHNA et al., 2004). Estudos mostraram que várias enzimas podem ser moduladas por EROs e, como a ausência da melatonina induz um desbalanço no estado redox intracelular, é provável que a melatonina participe da regulação do metabolismo da glicose controlando a ritmicidade cicardiana das enzimas antioxidantes ou pró-oxidantes, como a NADP(H) oxidase.

\subsection{O Complexo NAD(P)H oxidase}

A produção de EROs pela NAD $(\mathrm{P}) \mathrm{H}$ oxidase vem há muito tempo sendo considerada uma propriedade única de células fagocíticas do sistema imunológico, como neutrófilos, daí a origem do termo phox, abreviação de phagocyte oxidase. Nessas células a NAD(P)H oxidase tem como

função a produção de grandes quantidades de ânion superóxido para serem utilizadas contra microrganismos invasores. No entanto, mais recentemente vários trabalhos tem mostrado que 
outros tecidos expressam a $\mathrm{NAD}(\mathrm{P}) \mathrm{H}$ oxidase como as células endoteliais, fibroblastos, células musculares lisas (MEIER et al., 1991; GRIENDLING et al., 1994; GRIENDLING e USHIOFUKAI, 2000), assim como nas células beta pancreáticas (OLIVEIRA et al., 2003).

A NAD $(\mathrm{P}) \mathrm{H}$ oxidase é uma enzima heteromultimérica formada por proteínas localizadas na membrana plasmática e no citoplasma (Figura 2). As proteínas associadas à membrana plasmática formam uma flavohemeproteína heterodimérica conhecida como citocromo b558, ligadas a membranas de vesículas secretórias e grânulos citoplasmáticos, constituída pelos componentes gp91 ${ }^{\text {phox }}$ (glicoproteína) e p22 $2^{\text {phox }}$. A associação entre gp91 ${ }^{\text {phox }}$ e p22 phox se dá na proporção 1:1, pois apenas a união das duas subunidades gera um complexo estável para a ancoragem dos outros componentes da enzima (HEYWORTH; CROSS; CURNUTTE, 2003). Os demais componentes são citosólicos (p47 $7^{\text {phox }}, \mathrm{p} 67^{\text {phox }}, \mathrm{p} 40^{\text {phox }}$ além subunidade Rac e RhoGDI). A separação dessses componentes, citosólicos e de membrana, garante que a oxidase permaneça inativa (BABIOR, 2007; MIYAMO e SUMIMOTO, 2007).

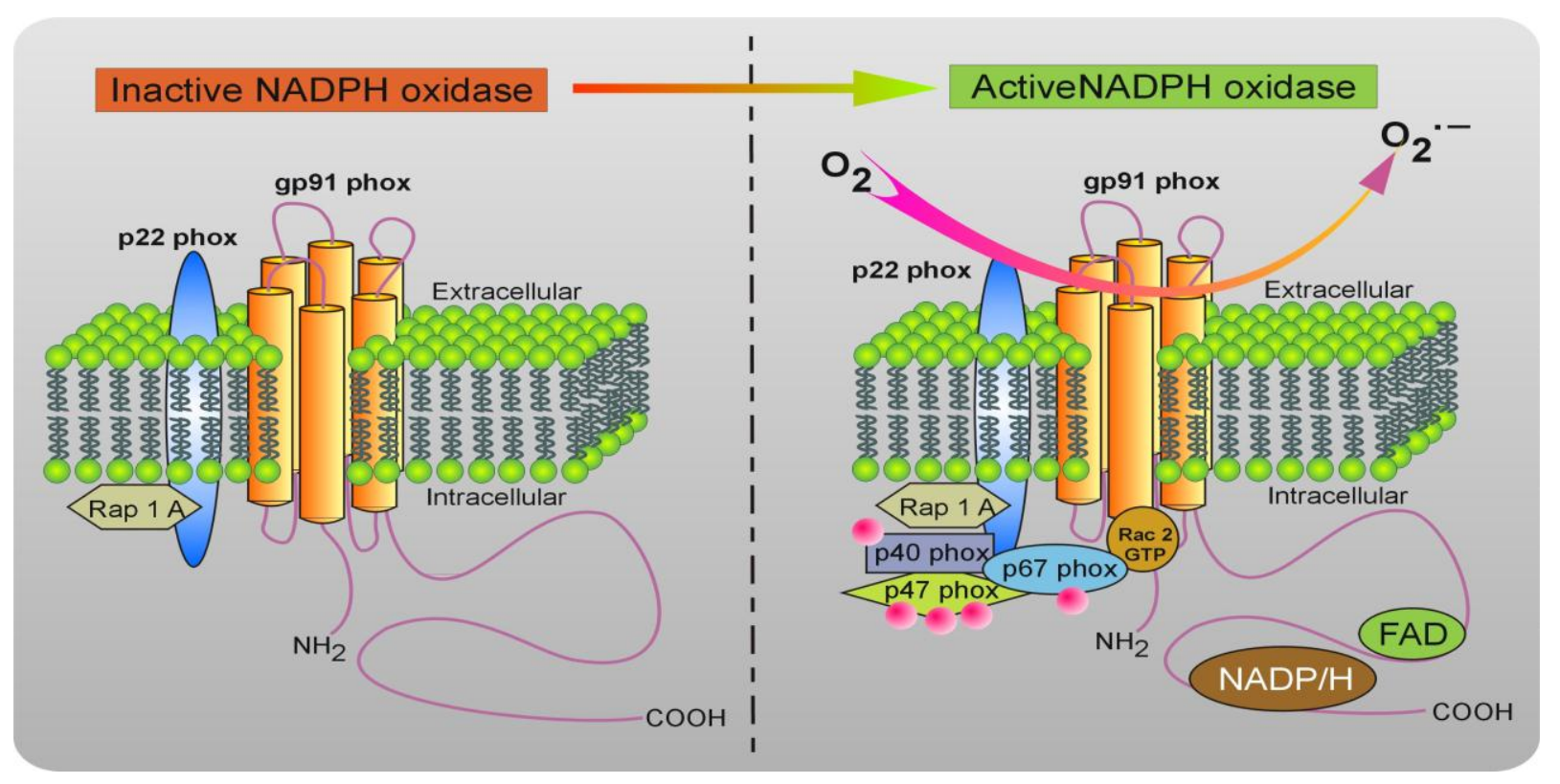

Figura 2 - Estrutura da enzima NAD(P)H oxidase em seu estado basal e ativado.

Fonte: www.genkyotex.com

Para tornar-se ativa, um processo bem coordenado de fosforilação, ativação de GTPase e interação entre proteínas deve ocorrer, sendo cada um desses, possíveis pontos de regulação para 
ativação da enzima (BOKOCH e ZHAO, 2006). Quando ocorre algum estímulo para ativação da enzima, os dois alvos a serem fosforilados são a p47 $7^{\text {phox }}$ e RhoGDI, que sofrem mudanças estruturais e permitem a migração dos componentes para a membrana (Figura 2). A subunidade p4 $7^{\text {phox }}$ é chamada de "subunidade organizadora" por não possuir atividade catalítica, mas quando fosforilada em resíduos de serina e treonina por quinases como PKC e Akt (FONTAYNE et al., 2002), cria condições para que a p67 $7^{\text {phox } ~ " s u b u n i d a d e ~ a t i v a d o r a " ~ s e ~ a s s o c i e ~ c o m ~ a ~ g p 91 ~}{ }^{\text {phox }} \mathrm{e}$ regule a redução do FAD pelo NADPH. A RhoGDI, quando fosforilada, permite a reposição do GTP na Rac, o que a torna ativa. A Rac-GTP migra independentemente para a membrana, mas de maneira coordenada com a p47 $7^{\text {phox }}$ e a p67 $7^{\text {phox }}$ e auxilia na ativação do centro catalítico através da sua interação direta com a oxidase e/ou com a p67 $7^{\text {phox }}$ (NAUSEEF, 2008).

A subunidade $\mathrm{p} 40^{\mathrm{phox}}$ parece exercer um papel importante no complexo enzimático, uma vez que foi verificada a redução da produção de EROs em camundongos Knockout para essa subunidade (ELLSON et al., 2006). A p40 ${ }^{\text {phox }}$ também pode ser fosforilada nos resíduos Thr154 e Ser315, o que é mediado em sua maior parte pela família das PKCs (BOUIN et al., 1998). No entanto, a importância da fosforilação da p40 phox ainda é desconhecida, embora tenha sido demonstrado que promova uma regulação negativa na função da NAD(P)H oxidase. (LOPEZ et al., 2007)

A p47 $7^{\text {phox }}$, quando fosforilada, organiza os demais componentes citoplasmáticos, ancorando-se com a p22 $2^{\text {phox }}$ e ativando o centro catalítico da enzima, a subunidade gp91 ${ }^{\text {phox }}$, que estará pronta para catalisar a produção de superóxido (BEDARD e KRAUSE, 2007). A subunidade gp91 ${ }^{\text {phox }}$ é formada por seis regiões transmembrana alfa-hélices em sua parte Nterminal, enquanto sua parte C-terminal é citoplasmática e possui os domínios de ligação ao FAD e NADPH, essenciais para sua atividade (HORDJK, 2006). Nas terceira e quinta hélices da proteína estão dois resíduos de histidina que são os prováveis ligantes de ferro dos dois grupos hemes não idênticos, sendo um externo à membrana e outro interno. Desse modo, como eles são perpendiculares à superfície da membrana, os elétrons são transferidos do NADPH citoplasmático para o FAD e, através da membrana, pelos grupamentos hemes até o oxigênio molecular, produzindo o radical superóxido.

Existe uma família de proteínas chamada de NOX/DUOX com sete membros, sendo todas proteínas homólogas a gp91 ${ }^{\text {phox }}$, que passou a ser chamada de NOX2. As outras são NOX1, 3, 4 e 
5 e DUOX1 e 2. A NOX1 é encontrada no colón, cérebro, e em células vasculares, a NOX2 em células fagocíticas do sistema imune, NOX3 no ouvido interno, NOX4 nos rins, osso e células sanguíneas, NOX5 em tecidos linfóides e nos testículos e as DUOX na tireóide (BEDARD; LARDY; KRAUSE, 2007). Elas diferem basicamente na dependência ou não de ativadores, na presença da subunidade $\mathrm{p} 22^{\text {phox }}$, de cofatores citoplasmáticos e de cálcio, na presença ou não de domínios EF-hands, que são responsáveis pela ligação ao cálcio e consequente modulação pelo mesmo (KRAUSE, 2004) (Figura 3). Além dessas proteínas homólogas a gp91 ${ }^{\text {phox }}$, existem outras subunidades, como a NOXO1 ou Proteína Organizadora de NOX, homóloga a p47 $7^{\text {phox }}$, e a NOXA1 ou Proteína Ativadora de NOX, homóloga a p67 ${ }^{\text {phox }}$, sendo que nem todas as NOX dependem dessas subunidades para a produção de superóxido.

Quanto ao destino da produção do superóxido produzido pela NAD(P)H oxidase, é sabido que nas células fagocíticas em seu estado inativo, a maior parte do flavocitocromo b558 é encontrado na membrana de vesículas citoplasmáticas e, ao ocorrer sua ativação, as vesículas são fundidas à membrana e a produção de superóxido ocorre no exterior da célula (BEDARD e KRAUSE, 2007). O superóxido produzido adentra a célula utilizando-se os canais 3 para cloreto, e o peróxido de hidrogênio oriundo de sua dismutação pela superóxido dismutase extracelular (SOD-EC) adentra a célula através de aquaporinas (FISHER, 2009).

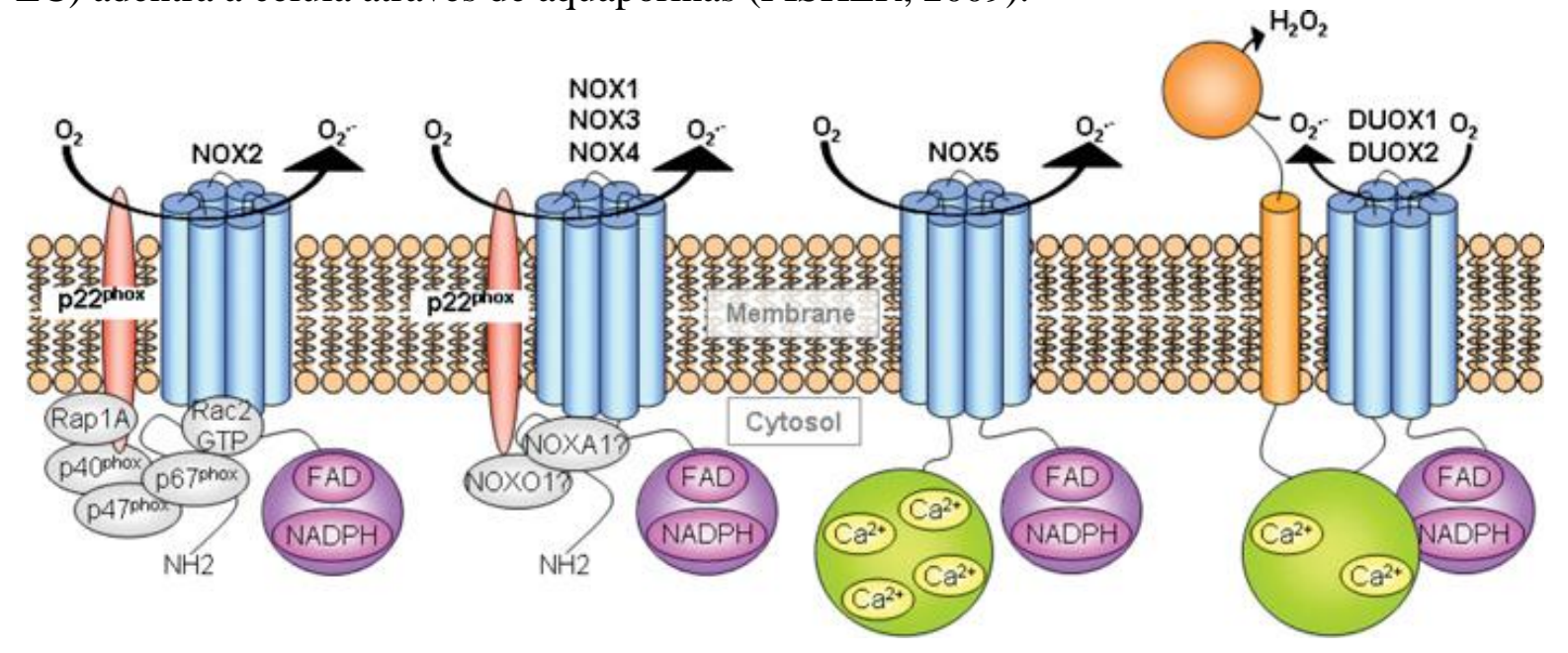

Figura 3 - Estrutura da família de enzimas NOX/DOUX. Enquanto NOX 1,2,3 e 4 são dependentes de p22PHOX, a NOX5 e as DUOX não são. Essas isoformas não dependem de subunidades regulatórias e são moduladas pelo cálcio, pois possuem o domínio EF_Hands de ligação ao íon.

FONTE: Krause, 2008

Nosso grupo de pesquisa demonstrou que células $\beta$ primárias expressam a enzima 
NAD(P)H oxidase (NOX2) (OLIVEIRA et al., 2003). Posteriormente, Uchizono et al. (2006) demonstraram através de experimentos realizados com RT-PCR e posterior sequenciamento, que além da NOX2, há a expressão da p22 $2^{\text {phox }}, \mathrm{p} 47^{\text {phox }}, \mathrm{P} 40^{\text {phox }}$, NOX1, NOX4, NOXO1 e NOXA1 pelas ilhotas pancreáticas (UCHIZONO et al., 2006). Em outro trabalho do nosso grupo, verificamos que a $\mathrm{NAD}(\mathrm{P}) \mathrm{H}$ oxidase pode ter sua atividade e expressão moduladas por glicose, citocinas e palmitato tanto em células $\beta$ primárias quanto em ilhotas pancreáticas de ratos (MORGAN et al., 2007; GRACIANO et al., 2010).

Com o intuito de verificar a função da enzima $\mathrm{NAD}(\mathrm{P}) \mathrm{H}$ oxidase em células $\beta$ pancreáticas, uma série de estudos foram realizados desde então. Uchizono et al. (2006) observaram que em alta concentração de glicose (16,7 mM de glicose), com a inibição da enzima por DPI (difenilenoiodonio, inibidor farmacológico da NAD(P)H oxidase), ocorre diminuição da secreção de insulina (UCHIZONO et al., 2006). Imoto et al. (2008) verificaram que a alteração provocada pelo DPI está relacionada a uma alteração na concentração intracelular de cálcio e sugeriram que a $\mathrm{NAD}(\mathrm{P}) \mathrm{H}$ oxidase possa modular a concentração deste íon nas células $\beta$ pancreáticas (IMOTO et al., 2008). Em estudo posterior, nosso grupo também demonstrou que a inibição da enzima utilizando DPI ou oligonucleotideo anti-sense para $\mathrm{p} 47^{\text {phox }}$ provocou redução da secreção de insulina estimulada por glicose, o que é acompanhado por uma diminuição da resposta de cálcio intracelular, da oxidação da glicose, da expressão gênica do transportador de glicose 2 (GLUT2) e da glicoquinase. Esses resultados demonstram a importância da produção de superóxido pela $\mathrm{NAD}(\mathrm{P}) \mathrm{H}$ oxidase durante o processo de secreção de insulina e no metabolismo da glicose nas células $\beta$ pancreáticas (MORGAN et al., 2009). 


\section{OBJETIVO}

O objetivo deste trabalho foi investigar, em ilhotas pancreáticas isoladas, a participação da enzima $\mathrm{NAD}(\mathrm{P}) \mathrm{H}$ oxidase no processo de secreção de insulina estimulada pela glicose em animais pinealectomizados, estudando, em particular:

- A expressão das subunidades (p22 ${ }^{\text {phox }}, \mathrm{p} 47^{\text {phox }}$, e gp91 ${ }^{\text {phox }}$ ) da enzima NAD(P)H oxidase nos ZTs -6 e 18 .

- A produção de superóxido nos ZTs - 6 e 18 após estimulo de glicose (5,6 e 16,7 mM).

- O metabolismo da glicose das ilhotas pancreáticas nos ZTs - 6 e 18 após o estimulo de glicose $(5,6$ e 16,7 mM);

- A secreção de insulina das ilhotas pancreáticas nos ZTs - 6 e 18 após o estimulo de glicose $(5,6$ e $16,7 \mathrm{mM})$ 


\section{MATERIAIS E MÉTODOS}

\subsection{Animais}

Foram utilizados ratos machos da linhagem Wistar, adultos, com idade aproximada de 45 dias e aproximadamente $200 \mathrm{~g} \pm 5 \%$ de peso corporal. Esses animais foram fornecidos pelo Biotério do Departamento de Fisiologia e Biofísica do Instituto de Ciências Biomédicas da Universidade de São Paulo (ICB/USP). Os animais foram mantidos em gaiolas coletivas (cinco por gaiola) em ambiente com temperatura constante em torno de $23 \pm 2{ }^{\circ} \mathrm{C}$ e sob ciclo de iluminação (claro/escuro) de 12/12 horas (acendimento das luzes artificiais às $6 \mathrm{~h}$ ), tendo livre acesso à água e dieta padrão composta por ração comercial. Os animais foram constituídos em dois grupos experimentais: Controle e pinealectomizados (PINX). O sacrifício dos animais dos dois grupos deu-se por decapitação, após um período de 45 dias da pinealectomia em dois horários ao longo do dia, denominado deste ponto em diante de ZT - Zeitgeber Time.

ZT é uma nomenclatura utilizada para uniformizar os horários do ciclo cicardiano sincronizado pelo claro-escuro ambiental, sendo que em ciclos de $12 \mathrm{~h} / 12 \mathrm{~h}$ claro/escuro que o ZT0 representa a transição do escuro para o claro (o início do claro) e que o ZT12, a transição do claro para o escuro (o início do escuro), independentemente do horário que se apagam as luzes.

Os procedimentos experimentais empregados no presente trabalho estão de acordo com os princípios Éticos de Experimentação Animal adotado pelo Colégio Brasileiro de Experimentação Animal (COBEA) e foram aprovados pela Comissão de Ética em Experimentação Animal (CEEA).

\subsection{Pinealectomia}

Assim que os animais completaram $\pm 200 \mathrm{~g}$, foi realizada a pinealectomia. Os animais foram anestesiados com uma mistura de Anasedan e Dopalen (0,15 ml / $100 \mathrm{~g})$, sendo fixado em aparelho estereotáxico, e submetido à cirurgia de acordo com o método de Hoffman e Reiter (1965) . Foi realizada uma abertura sagital a fim de expor a sutura lambdóide. Por meio de uma broca circular, uma perfuração em forma de disco foi feita na calota craniana, e logo após, o disco foi removido delicadamente. Em seguida, a glândula pineal, localizada logo abaixo da 
confluência venosa posterior, foi removida com auxilio de uma pinça. Após um breve período de hemóstase, recolocou-se o disco de osso na abertura feita no crânio e o escalpo foi suturado.

\subsection{Isolamento das Ilhotas Pancreáticas}

A obtenção das ilhotas foi realizada pelo método da digestão do pâncreas exócrino pela colagenase, e acordo com técnicas já estabelecidas (LACY e KOSTIANOVSKY, 1967). Os animais foram decapitados e submetidos a sepsia da região abdominal com álcool 70\%. Foi realizada a laparotomia mediana e a exposição do ducto biliar comum, que foi clampeado na sua extremidade distal e dissecado próximo ao pedículo hepático, por onde foi introduzida uma agulha acoplada a cânula de polietileno e injetados, por via retrógrada, cerca de $20 \mathrm{~mL}$ de colagenase tipo V a 0,7mg/mL da Sigma (Sigma Chemical Co., St. Lous, MO, EUA) em Hanks. A solução de Hanks contém Nacl $8.00 \mathrm{~g} / \mathrm{L}, \mathrm{KCl}$ 0,40 g/L, $\mathrm{CaCl}_{2}$ 0,14 g/L, $\mathrm{MgSO}_{4} .7 \mathrm{H}_{2} \mathrm{O}$ 0,20 $\mathrm{g} / \mathrm{L}, \mathrm{NaH}_{2} \mathrm{PO}_{4} 0,48 \mathrm{~g} / \mathrm{L}, \mathrm{KH}_{2} \mathrm{PO}_{4} 0,06 \mathrm{~g} / \mathrm{L}, \mathrm{NaHCO}_{3}$ 0,35 g/L, $\mathrm{H}_{2} \mathrm{O}$ (qsp): 1,00 L

A solução flui através dos ductos pancreáticos, provocando o preenchimento do tecido acinar. O pâncreas foi retirado e colocado em placa de Petri para dissecação de gânglios linfáticos, tecido adiposo e vasos sanguíneos, foi fragmentado em pedaços de aproximadamente $1,5 \mathrm{~cm}^{3}$ e depositado em tudo de ensaio de $9,5 \times 5 \mathrm{~cm}$. O tudo foi colocado em banho a $37{ }^{\circ} \mathrm{C}$ durante 25 minutos. A seguir, foi agitado manualmente a $37^{\circ} \mathrm{C}$ por 1 minuto para a digestão da porção exócrinas do pâncreas. O conteúdo foi transferido para um Becker com solução de Hanks gelado e lavadas quatro vezes. Em placa de Petri foi realizada a coleta das ilhotas pancreáticas com o emprego de micropipeta e lupa.

\subsection{Western Blotting}

Amostras com cerca de 350 ilhotas foram homogeneizadas em sonicador com tampão de extração (1\% de Triton-X 100, 100mM de Tris pH 7,4, $100 \mathrm{mM}$ de pirofosfato de sódio, $100 \mathrm{mM}$ de fluoreto de sódio, $10 \mathrm{mM}$ de EDTA, $10 \mathrm{Mm}$ de ortovanadato de sódio, $2 \mathrm{mM}$ de PMSF (fenilmetilsulfonil fluoreto) e $0,01 \mathrm{mg} / \mathrm{ml}$ de aprotinina), em seguida foram fervidas durante 5 minutos e centrifugadas a $12000 \mathrm{rpm}$, durante 20 minutos a $4{ }^{\circ} \mathrm{C}$ para remoção do material insolúvel. Parte do sobrenadante foi utilizada para determinação do conteúdo protéico por espectrofotometria, utilizando-se o reagente para ensaio de proteína "BioRad Protein Assay-Dye 
Reagent Concentrate" (Bio-Rad, Melville, NY, EUA) e curva padrão de albumina bovina como referência. $\mathrm{O}$ restante do sobrenadante foi diluído em tampão Leammli (azul bromofenol 0,1\%, 1 M fosfato de sódio pH 7,0, glicerol 50\% e SDS 10\%) contendo 200 mM de DTT (ditiotreitol), em proporção de 5:1, sendo as amostras mantidas a $-20{ }^{\circ} \mathrm{C}$ até sua utilização. As amostras em tampão Leammli foram fervidas durante 5 minutos antes de serem aplicadas em gel de poliacrilamida.

Cerca de 30 a $50 \mu$ g de proteína total foi submetido à eletroforese em gel bifásico: gel de empilhamento e gel de resolução de 8 a $12 \%$ em aparelho para minigel de poliacrilamida (MiniProtein, Bio-Rad), juntamente com o marcador molecular pré-corado disponível comercialmente (Bio-Rad). A transferência das proteínas foi feita eletricamente para uma membrana de nitrocelulose (Amersham BioSciences, USA), utilizando aparato para transferência (Bio-Rad) e realizada durante 90 minutos a $120 \mathrm{~V}$ em gelo, banhada em tampão de transferência.

Após a transferência, as membranas foram incubadas em solução bloqueadora $(5 \%$ de leite desnatado Molico® - Nestlé (Nestlé Brasil Ltda., Araçatuba, SP, Brasil) em solução basal composta por $10 \mathrm{mM}$ Tris, $150 \mathrm{mM} \mathrm{Nacl} \mathrm{e} \mathrm{0,02 \%} \mathrm{Tween} \mathrm{20)} \mathrm{a} 4{ }^{\circ} \mathrm{C}$ overnight ou à temperatura ambiente, durante 2 horas. Após, as membranas foram lavadas 3 vezes durante 10 minutos com solução basal sob agitação. Posteriormente, as membranas foram incubadas com anticorpos nas concentrações descritas na Tabela 1 , overnight a $4{ }^{\circ} \mathrm{C}$.

Após a incubação, as membranas foram lavadas 3 vezes durante 10 minutos com solução basal sob agitação e incubadas, à temperatura ambiente, com anticorpos secundários anti-IgG ligados a peroxidase, por 1 hora. Em seguida, as membranas foram lavadas com solução basal sob agitação e reveladas. Para revelação utilizamos os reagentes de quimioluminescência ECL da Millipore. As soluções 1 e 2 foram adicionadas na mesma proporção, recobrindo as membranas e, após 1 minuto de reação, as membranas foram ensacadas e expostas, protegida da luz, ao filme de raio-X ou analisadas no aparelho ImageQuant, GE Healthare (GE HealthareAS, Oslo, Noruega) A intensidade das bandas reativas formadas foi quantificada por densitometria óptica utilizando o programa Image J. (Wayne Rasband, National Institutes of Health, USA). 
Tabela 1- Anticorpos utilizados e suas respectivas concentrações.

\begin{tabular}{|c|c|c|}
\hline Anticorpo & Animal de Origem & Immunoblotting \\
\hline $\begin{array}{c}\text { Policlonal anti-p47 } \\
\text { (Upsox } \\
\text { (Utate Cell Signalling Solutions) }\end{array}$ & Coelho & $1: 500$ \\
\hline $\begin{array}{c}\text { Policlonal anti-gp91 } \\
\text { (Upstate Cell Signalling Solutions) }\end{array}$ & Coelho & $1: 1000$ \\
\hline $\begin{array}{c}\text { Policlonal anti-p22 } \\
\text { (SHoxta Cruz Biotechnology- Santa Cruz, CA) }\end{array}$ & Coelho & $1: 500$ \\
\hline $\begin{array}{l}\text { Monoclonal anti- } \alpha \text { Tubulina } \\
\text { (Zymed - San Francisco, CA) }\end{array}$ & Camundongo & $1: 2000$ \\
\hline anti-IgG de coelho ligado à peroxidase (Amersham Biosciences, USA) & Camundongo & $1: 10.000$ \\
\hline anti-IgG de camundongo ligado à peroxidase (Amersham Biosciences, USA) & Coelho & $1: 10.000$ \\
\hline
\end{tabular}




\subsection{Análise do Conteúdo Intracelular das Espécies Reativas de Oxigênio}

$\mathrm{O}$ conteúdo de superóxido $\left(\mathrm{O}_{2}{ }^{\circ-}\right)$ foi determinado utilizando o método de fluorescência com dihidroetídeo (BINDOKAS et al., 2003). A Hidroetidina (EH) ou Diidroetídeo (DHE) é uma sonda redox-sensível, extensamente usada para detectar a produção intracelular de ânion superóxido. A reação entre o superóxido e o DHE resulta na formação de um produto oxidado, o etídeo $\left(\mathrm{E}^{+}\right)$, este se intercala entre as bases de DNA, corando o núcleo com uma fluorescência vermelha (ZHAO et al., 2003).

Grupos de 20 ilhotas foram incubadas durante 30 minutos em uma solução de Krebs Henseleit na presença de 0,2\% de albumina em 5,6 mM e 16,7 mM glicose, em banho-maria sob agitação, à $37^{\circ} \mathrm{C}$. Em seguida adicionou-se a hidroetidina em concentração final de $50 \mu \mathrm{M}$ e incubou-se por 20 minutos, a temperatura ambiente. Após a incubação, a solução de incubação é retirada, as ilhotas são lavadas em Krebs-Henseleit e transferidas para lâminas de cultura (Chamber slide system).

A produção da fluorescência foi analisada em microscópio confocal (LSM 510 Aaxiovert 100M - Carl Zeiss; Jena - Germany). Para tanto, as ilhotas foram submetidas à excitação com laser de Hélio-neônio no comprimento de onda 488nm, sendo a emissão capturada no comprimento de 566nm. A obtenção das imagens foi realizada com uma objetiva de 40x, sendo utilizados parâmetros idênticos entres as amostras de uma mesma seqüência experimental. Para a quantificação da fluorescência foi feita a projeção das secções e utilizado o programa Image J. (Wayne Rasband, National Institutes of Health, USA). Os dados foram expressos pela área da ilhota pancreática analisada.

\subsection{Análise da Secreção Estática de Insulina em Ilhotas Pancreáticas}

Para avaliação da secreção estática de insulina, foram utilizados grupos de cinco ilhotas em triplicata para cada condição experimental. As amostras foram pré-incubadas em $500 \mu 1$ de Krebs-Henseleit em 5,6 mM glicose suplementado com albumina bovina (0,2\%), e incubadas em 5,6 e 16,7 mM, permanecendo em banho a $37{ }^{\circ} \mathrm{C}$ por 60 minutos. Após o período de incubação, $450 \mu \mathrm{l}$ do sobrenadante foi removido e estocado a $-20{ }^{\circ} \mathrm{C}$ para posterior dosagem de insulina por radioimunoensaio. 
As ilhotas foram posteriormente ressuspendidas em $450 \mu \mathrm{L}$ de uma solução de álcool ácido (52 mL etanol, $17 \mathrm{~mL}$ água, $1 \mathrm{~mL}$ ácido clorídrico) e rapidamente sonicadas, provocando o rompimento das células para dosagem do conteúdo intracelular de insulina.

\subsection{Dosagem de Insulina}

A determinação da quantidade de insulina secretada foi determinada por radioimunoensaio. Para tanto, a solução reagente inclui uma quantidade conhecida de anticorpo, uma quantidade conhecida do hormônio marcado radioativamente (insulina marcada com iodo -

${ }^{125}$ I, Amershan Biosciences, Inglaterra) e uma quantidade desconhecida de hormônio nãoradioativo (amostra). Como as duas formas de hormônio, radioativo e não-radioativo, competem por um mesmo número de locais de ligação ao anticorpo, quanto mais hormônio não-radioativo estiver presente, menos o hormônio radioativo irá se ligar. O complexo insulina-anticorpo marcado formado foi precipitado com polietilenoglicol (PM 6000) e dosado em contador tipo gama (PerkinElmer, Turku, Finlândia). Uma curva padrão foi preparada, na qual a relação ligado/livre para o hormônio radioativo é plotada com função da concentração do hormônio não radioativo. A relação ligado/livre do hormônio radioativo é maior quanto menor número de não radioativo estiver presente. A curva padrão foi utilizada para determinar a concentração do hormônio em cada amostra.

\subsection{Análise do Metabolismo da $\left[{ }^{14} \mathrm{C}\right]-$ Glicose}

Grupos de ilhotas pancreáticas foram incubadas em 1,2 mL de Krebs-Henseleit contendo $0,2 \%$ de albumina em 5,6 mM e 16,7 mM glicose durante 60 minutos a $37^{\circ} \mathrm{C}$. As ilhotas foram incubadas em tubos de vidro os quais continham, em compartimento separado, papel de filtro (2,5 x $3 \mathrm{~cm}$ ) embebido em $400 \mu \mathrm{L}$ de feniletilamina, diluída 1:1 v/v em metanol. A solução de incubação continha glicose uniformemente com carbono $14\left(\left[\mathrm{U}_{-}{ }^{14} \mathrm{C}\right]\right)$, na atividade de $0,2 \mu \mathrm{Ci} / \mathrm{mL}$ para a solução de 5,6 mM e $0,6 \mu \mathrm{Ci} / \mathrm{mL}$ para a solução $16,7 \mathrm{~mm}$ glicose. A incubação foi interrompida pela adição de $400 \mu \mathrm{L}$ de ácido clorídrico $(10 \mathrm{M})$, às amostras e os tubos foram agitados por 1 hora e 30 minutos. O papel de filtro contendo feniletilamina foi transferido para tubos de cintilação e posterior adição de $1,8 \mathrm{~mL}$ de líquido de cintilação biodegradável (Amershan Pharmacia, Upsala Sweden) e o ${ }^{14} \mathrm{CO}_{2}$ adsorvido pela feniletilamina foi medido por 
Cintilador Beckman-LS 5000TD (Beckman Instruments, Fullerton, CA, USA). A descarboxilação da $\left[\mathrm{U}_{-}{ }^{14} \mathrm{C}\right] \mathrm{D}$-glicose estima o fluxo metabólico pela via glicolítica.

\subsection{Análise Estatística}

Os resultados foram apresentados como média \pm erro padrão da média (EPM). O intervalo mínimo de significância considerado foi de $95 \%$ ( $p<0,05)$. Para cada seqüência experimental as diferenças entre as condições foram determinadas por analise da variância (ANOVA), de uma ou duas vias, seguido de comparações entre as condições pelo pós-teste Tukey ou Bonferroni respectivamente. Para seqüências experimentais com apenas duas condições, a diferença foi determinada por teste " $\mathrm{t}$ " de student. O programa utilizado para analise estatística foi o Graphpad Prism data analysis and package (v4.03, Graphpad Sohtware, Inc., San Diego Califórnia, EUA). 


\section{RESULTADOS E DISCUSSÃO}

\subsection{Avaliação do Conteúdo de Superóxido no ZT - 6 e ZT - 18}

Tendo como objetivo estudar os efeitos da melatonina sobre a funcionalidade das células $\beta$ pancreáticas, optamos pela utilização de animais pinealectomizados como modelo experimental. Considerando que o ritmo de secreção do hormônio da pineal, é parcialmente responsável pela ritmicidade da secreção de insulina e do metabolismo da glicose nas células $\beta$ pancreáticas, dispusemo-nos a verificar se esse controle exercido, fundamentalmente pela melatonina, tem ou não participação da enzima $\mathrm{NAD}(\mathrm{P}) \mathrm{H}$ oxidase.

Levando-se em conta que a produção de superóxido é proveniente da cadeia de transporte de elétrons na mitocôndria e, em diversos tecidos, como ilhotas pancreáticas, a NAD(P)H oxidase é também uma importante fonte de superóxido (BABIOR, 1999; MORGAN et al., 2007; MORGAN et al., 2009; GRACIANO et al., 2010), analisamos em animais normais e pinealectomizados o conteúdo total de superóxido produzido pela ilhota pancreática quando estimulada por diferentes concentrações de glicose.

As ilhotas pancreáticas dos animais PINX no ZT-6, apresentaram um aumento de 56\% no conteúdo intracelular de superóxido após 30 minutos de incubação na presença de 5,6 mM glicose (Figura 4a) quando comparadas com às do animal controle. Esse resultado pode ser devido ao possível aumento da atividade da $\operatorname{NADP}(\mathrm{H})$ oxidase induzido pela ausência crônica de melatonina e suas ações antioxidantes. É sabido que, além da interação direta com EROs (REITER et al., 2008), a melatonina reduz a expressão e a atividade da NAD(P)H oxidase (ZHOU et al., 2008), que é um potente formador de EROs nas ilhotas pancreáticas (MORGAN et al., 2007; MORGAN et al., 2009; GRACIANO et al., 2010). Dados não publicados do nosso laboratório mostraram que a melatonina reduz a formação de EROs em ilhotas isoladas de ratos com redução da expressão da subunidade $\mathrm{p} 22^{\text {phox }}$. Por outro lado, o animal PINX perde a capacidade de regular e manter o equilíbrio redox, apresentando aumento da formação de EROs, possivelmente pela atividade da $\mathrm{NAD}(\mathrm{P}) \mathrm{H}$ oxidase e da cadeia de transporte de elétrons da mitocôndria (BABIOR, 2002; BAYDAS et al., 2002; LOPEZ et al., 2009). 
Nossos experimentos mostraram que na presença de $16,7 \mathrm{mM}$ glicose, o conteúdo de superóxido das ilhotas isoladas não apresentou alteração em ambos os grupos, com valores semelhantes àquelas incubadas na presença de 5,6 mM do açúcar (Figura 4a). Esse dado pode ser explicado pelas observações de Oliveira et al. (1999), que mostraram que, agudamente, (60 min de incubação), as ilhotas pancreáticas apresentam aumento da atividade da enzima superóxido dismutase (SOD) em resposta ao aumento da concentração de glicose (OLIVEIRA; CURI; CARPINELLI, 1999). Além disso, a enzima antioxidante catalase, apresenta um ritmo ultradiano de atividade, com pico até 17 horas após o início do ciclo claro/escuro (SANI et al., 2006), o que corresponde ao ZT-5 (próximo ao ZT-6).

No rato, o ZT-18 corresponde ao momento de maior atividade, maior ingesta de alimentos e à presença do pico de melatonina. Após 30 minutos de incubação na presença de 5,6 mM glicose neste ZT, as ilhotas pancreáticas dos animais PINX apresentam um aumento de $40 \%$ na produção de EROs em relação ao grupo controle (Figura 4b), resultado semelhante ao encontrado no ZT-6 (Figura 4a), embora não diferente estatisticamente. Na presença de 16,7 mM glicose, observamos aumento de $69 \%$ e $63 \%$ na produção de EROs pelas ilhotas do grupo controle e pinealectomizado respectivamente.

A produção de EROs observada em baixa glicose no ZT-18 (Figura 4b), pode ser devida à participação da $\mathrm{NAD}(\mathrm{P}) \mathrm{H}$ oxidase. De maneira semelhante ao ZT-6, esse fenômeno seria mediado pela ausência da melatonina, que sabidamente, influência na expressão e atividade da enzima (ZHOU et al., 2008), além de interferir na ritmicidade das enzimas antioxidantes alterando o estado redox de diversos tecidos (BAYDAS et al., 2002). Entretanto, em alta concentração do açúcar (Figura 4b), notamos que ambos os grupos exibiram elevada produção de superóxido, resultado divergente do observado no ZT-6, indicando uma possível oscilação cicardiana na produção de EROs, que pode ser dependente da ritmicidade das enzimas antioxidantes (BAYDAS et al., 2002). Todavia, no ZT-18 as ilhotas pancreáticas se encontravam banhadas por altas concentrações de glicose (KALSBEEK et al., ; LA FLEUR et al., 2001), e como as ilhotas possuem a capacidade de manter a memória do horário de retirada (DELATTRE; CIPOLLA-NETO; BOSCHERO, 1999), isso confere aumento da oxidação do nutriente e consequentemente provoca acréscimo da produção de superóxido tanto pela mitocôndria, como pela NAD(P)H oxidase, além do possível crosstalk entre essas duas vias (MORGAN et al., 2007; 
WENZEL et al., 2008; LOPEZ et al., 2009; WOSNIAK et al., 2009).

Esses resultados mostram que a ausência crônica de melatonina altera o estado redox das ilhotas pancreáticas em baixa concentração de glicose, podendo esse fenômeno ser mediado pela NAD(P)H oxidase, induzindo um desbalanço na produção de superóxido no ZT-6 e ZT-18. Entretanto, em alta glicose, no ZT-6, esse efeito não pode ser observado, possivelmente pelo aumento da atividade da SOD induzido pela glicose. Contudo, no ZT-18, altas concentrações de glicose induzem o aumento da produção de EROs, possivelmente mediado pela NAD $(\mathrm{P}) \mathrm{H}$ oxidase e pela cadeia de transporte de elétrons da mitocôndria relacionado ao período alimentar.

Estudos mostram que elevada produção de EROs induz o estresse oxidativo e consequente comprometimento das células $\beta$ pancreáticas (MOORE et al., 2004; TANG et al., 2007). Sabidamente, a pinealectomia além de induzir a resistência à insulina (LIMA et al., 1998), modifica a ritmicidade da secreção desse hormônio (PICINATO et al., 2002a). Podemos especular que, à longo prazo, os animais PINX poderão apresentar deficiência da secreção de insulina, podendo desenvolver diabetes mellitus, provavelmente, mediado pelo estresse oxidativo. 
A.

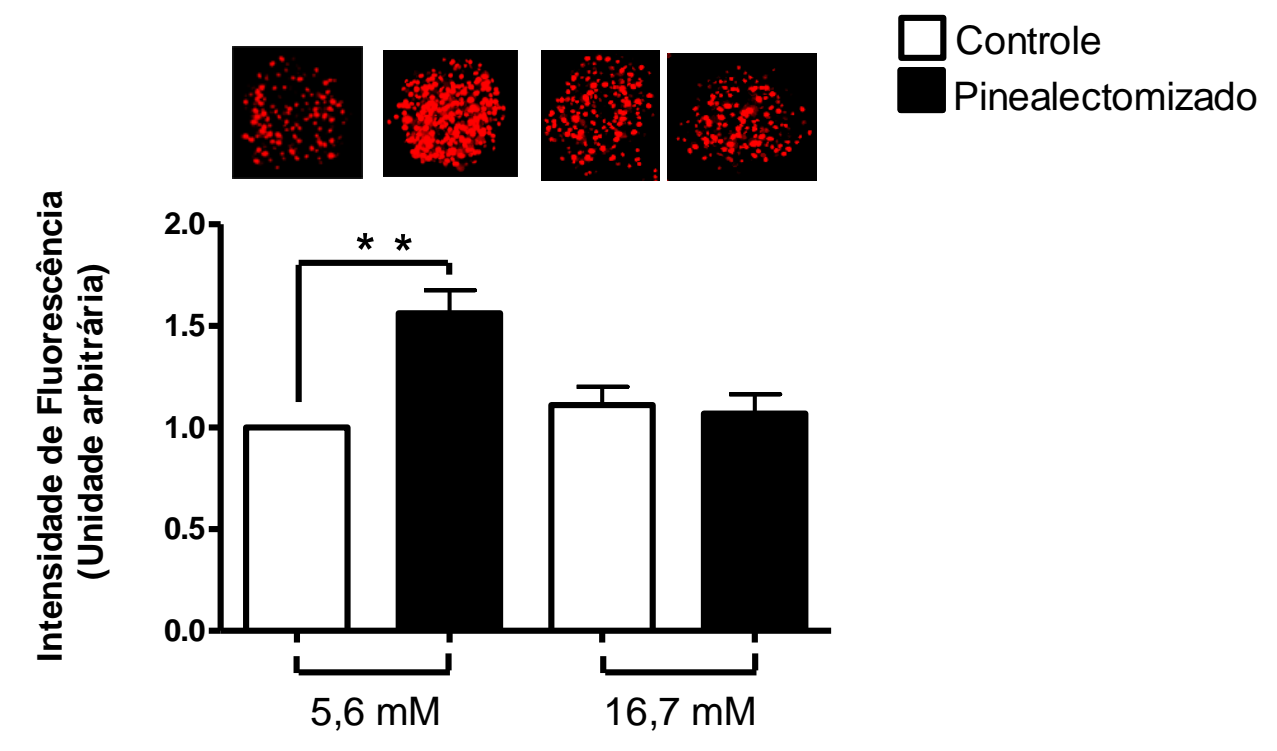

B.
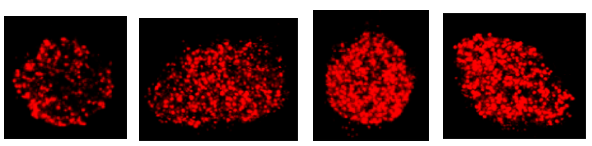

$\square$ Controle Pinealectomizado

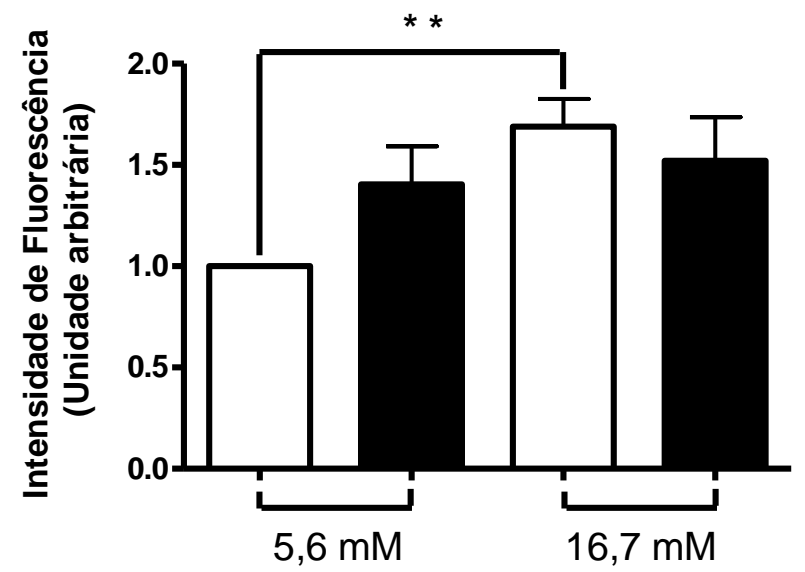

Figura 4 - Efeito da glicose sobre o conteúdo intracelular de superóxido em animais controle e pinealectomizado

Ilhotas pancreáticas foram incubadas durante 30 minutos em 5,6 e 16,7 mM glicose, (A) ZT-6 e (B) ZT-18. Os resultados estão expressos como média \pm erro padrão da média $(\mathrm{n}=9)$. One-way ANOVA, Tukey's multiple comparison test. **p<0,01 


\subsection{Avaliação do Metabolismo da $\left[{ }^{14} \mathrm{C}\right]-$ Glicose no ZT-6 e ZT-18}

A $\mathrm{NAD}(\mathrm{P}) \mathrm{H}$ oxidase, por mecanismos que ainda não foram totalmente esclarecidos, participa da funcionalidade das células $\beta$ pancreáticas. Estudos do nosso grupo de pesquisa mostraram que a inibição da $\mathrm{NAD}(\mathrm{P}) \mathrm{H}$ oxidase, reduz a oxidação da glicose (MORGAN et al., 2007; MORGAN et al., 2009). Por outro lado, a melatonina exerce um efeito inibitório sobre a NAD(P)H oxidase (ZHOU et al., 2008).

Dentro desse contexto verificamos que no ZT-6, na presença de 5,6 mM glicose, as ilhotas dos animais PINX apresentaram uma redução de 32,2\% na oxidação da glicose (Figura 5a). Na presença de 16,7 mM glicose, a oxidação do açúcar no grupo PINX apresentou um aumento de 49,8\% em relação ao grupo controle (Figura 5a).

A ausência crônica de melatonina, no ZT-6, induziu a um provável desbalanço no estado redox das ilhotas pancreáticas em baixa concentração de glicose (Figura 4a), possivelmente pela atividade da $\mathrm{NAD}(\mathrm{P}) \mathrm{H}$ oxidase aumentando a produção de EROs e consequentemente reduzindo o metabolismo da glicose. A inibição da maquinaria metabólica pelas EROs, pode ocorrer em consequência do bloqueio da atividade da enzima mitocondrial aconitase (BULTEAU, 2003) e da enzima citosólica gliceraldeído 3-fosfato desidrogenase (G3PD), as quais são susceptíveis à modulação oxidativa (LIND et al., 1998).

A oxidação do grupamento tiol da G3PD bloqueia a atividade enzimática, pois é o sítio responsável pela ligação ao gliceraldeído 3-fosfato (LIND et al., 1998). De modo semelhante, a atividade da aconitase é também susceptível a mecanismos oxidativos. A aconitase mitocondrial pertence a uma família de desidratases contendo ferro-enxofre, nas quais a atividade é dependente do estado redox dos grupamentos $[4 \mathrm{Fe}-4 \mathrm{~S}]^{2+}$. Assim, tem sido demonstrada que a exposição de mitocôndria isolada a oxidantes, em particular o superóxido e o peróxido de hidrogênio, a enzima torna-se inativa, impedindo a conversão de citrato para isocitrato (BULTEAU, 2003).

Entretanto, como na presença de $16,7 \mathrm{mM}$ de glicose não observamos aumento do conteúdo de EROs (Figura 4a), a oxidação da glicose pelas células $\beta$ pancreáticas nessa mesma concentração do açúcar não foi suprimida por EROs. A não alteração do conteúdo de EROs neste caso, pode ter ocorrido devido ao aumento da atividade da enzima antioxidante SOD que ocorre na presença de altas concentrações de glicose (OLIVEIRA; CURI; CARPINELLI, 1999). Dessa 
forma, enzimas como a G3PD e a aconitase não sofreram modulação oxidativa e mantiveram sua funcionalidade, visto que a oxidação da glicose na presença de $16,7 \mathrm{mM}$ do açúcar apresenta um aumento de 49,8\% no grupo PINX quando comparado ao grupo controle (Figura 5a), semelhante ao observado por outros autores (PICINATO et al., 2002a).

Ao contrario do observado no ZT-6, a oxidação da glicose no ZT-18 esta aumentada muito provavelmente por ser o período de atividade alimentar favorecendo o aumento do metabolismo da ilhota. A pinealectomia, no ZT-18 induziu um aumento de $92 \%$ na oxidação da glicose na presença de 5,6 $\mathrm{mM}$ do açúcar e de 60,2\% na presença de 16,7 $\mathrm{mM}$ glicose (Figura $5 b)$.

Por outro lado, na presença de $16,7 \mathrm{mM}$ glicose, a pinealectomia induziu aumento de 60,2\% na oxidação da glicose (Figura 5b). O aumento da atividade da SOD induzido pela concentração de glicose (OLIVEIRA; CURI; CARPINELLI, 1999) provavelmente não foi suficiente para prevenir de EROs. A não redução do metabolismo das ilhotas pelo elevado acúmulo de EROs não ocorreu provavelmente por interferência de outros fatores como o aumento da atividade física e ou consumo alimentar dos animais no período estudado.

Nossos dados sugerem que, a oxidação da glicose está estreitamente correlacionada ao equilíbrio redox intracelular, sendo a $\mathrm{NAD}(\mathrm{P}) \mathrm{H}$ oxidase um importante modulador desse processo. 
A.

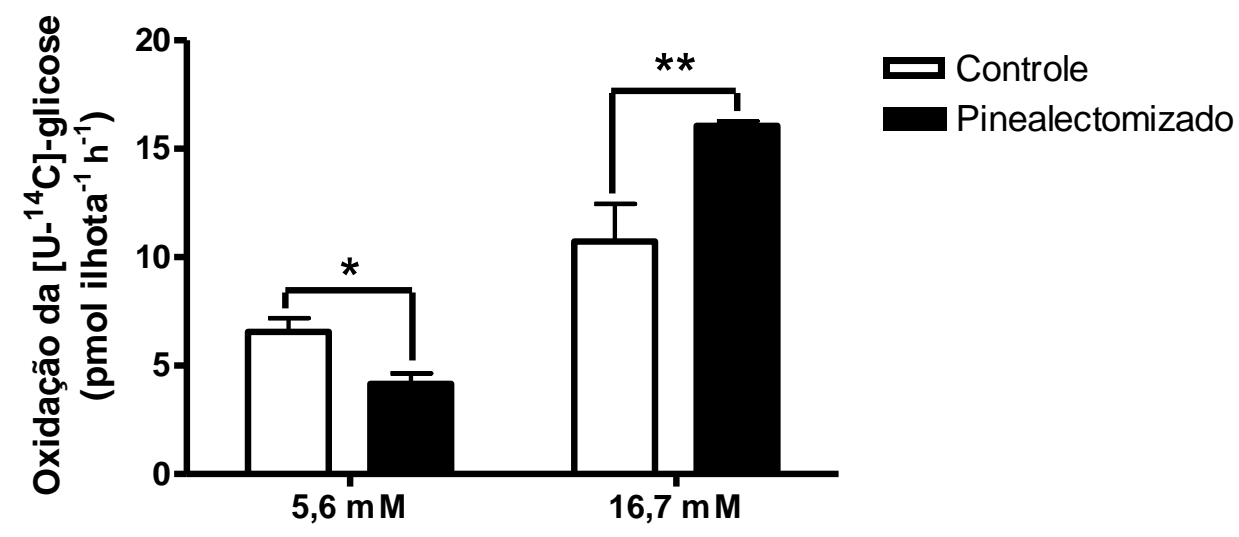

B.

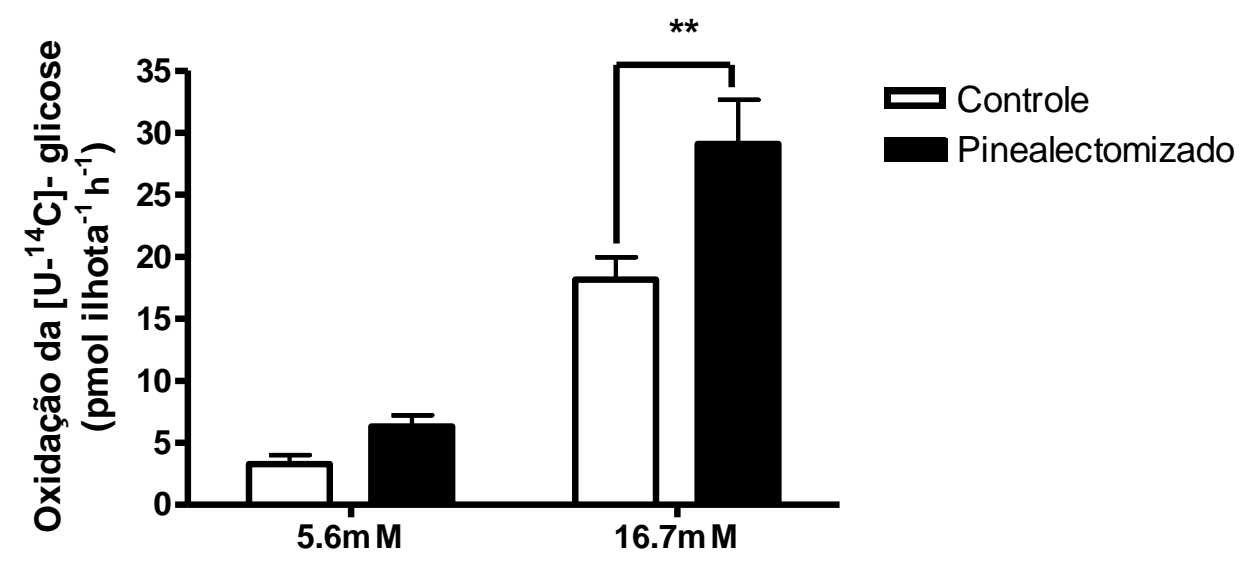

Figura 5 - Análise do metabolismo da $\left[{ }^{14} \mathrm{C}\right]$-Glicose nos animais controle e pinealectomizados

Ilhotas pancreáticas isoladas foram incubadas durante 60 minutos em 5,6 e 16,7 mM glicose, (A) ZT-6 e (B) ZT-18. Os resultados são expressos em média \pm EP (n=5). Two-way ANOVA, Bonferroni posttests. $* \mathrm{p}<0,05, * * \mathrm{p}<0,01$ 


\subsection{Avaliação da Secreção Estática de Insulina no ZT-6 e ZT-18}

A supressão no metabolismo da glicose em resposta a alteração do conteúdo de intracelular de superóxido induzido pela ausência da melatonina, no ZT-6, na presença de 5,6 mM glicose, não modificou a secreção basal de insulina (Figura 6a). Na presença de 16,7 mM do açúcar, verificamos que a pinealectomia induziu um aumento de $48 \%$ na secreção de insulina quando comparado ao grupo controle (Figura 6a). No ZT-18, na presença de 5,6 mM glicose, as ilhotas isoladas de ratos PINX não apresentaram diferença na secreção basal de insulina (Figura 6b), semelhante ao observado no ZT-6. Na presença de 16,7 mM do açúcar, a pinealectomia altera em 42,5\% a secreção de insulina (Figura 6b), consequência do aumento da oxidação da glicose.

Esses resultados mostram que ilhotas isoladas de ratos PINX, no ZT-6 e ZT-18, exibem elevada resposta secretória em relação ao grupo controle. É sabido que, ratos PINX, perdem a capacidade de manter a ritmicidade cicardiana da secreção de insulina estimulada pela glicose, apresentando um adiantamento de fase da curva diária de quase 3 horas do pico de secreção do hormônio (PICINATO et al., 2002a). Enquanto que, ilhotas pancreáticas na presença da melatonina, após um período de inibição, proporciona uma melhora da capacidade das ilhotas em secretar insulina (PESCHKE e PESCHKE, 1998). Além disso, Delattre et al. (1999) observaram que no inicio do período noturno ilhotas isoladas apresentam uma maior capacidade secretória em resposta ao mesmo estímulo de glicose (DELATTRE; CIPOLLA-NETO; BOSCHERO, 1999).

La Fleur et al. (2001) observaram que ratos PINX apresentaram um aumento da concentração plasmática de glicose no fim do período noturno, sem modificação na concentração plasmática de insulina (LA FLEUR et al., 2001), de maneira semelhante, Lima et al. (1998) mostraram pelo teste de tolerância a glicose intravenoso (IVGTT), que a pinealectomia não altera a concentração plasmática de insulina no fim do período diurno (LIMA et al., 1998). Verifica-se que a pinealectomia induz respostas distintas no modelo in vitro e in vivo no processo de secreção

de insulina estimulada pela glicose, possivelmente pela ação de moduladores da secreção de insulina que estão presentes no modelo in vivo, como a cortisterona.

A $\mathrm{NAD}(\mathrm{P}) \mathrm{H}$ oxidase é consideravelmente importante no processo de secreção de insulina, sendo modulada por diferentes nutrientes, como glicose e ácido graxo (MORGAN et al., 2009; GRACIANO et al., 2010). A melatonina por modular a secreção de insulina pelas células $\beta$ pancreáticas (PESCHKE et al., 2002; PICINATO et al., 2002b; STUMPF; BAZWINSKY; 
PESCHKE, 2009) e exercer ação sobre a NAD(P)H oxidase (ZHOU et al., 2008), torna-se importante na funcionalidade das células $\beta$ pancreáticas. Podemos especular que, a ausência da melatonina, modifica a atividade da $\mathrm{NAD}(\mathrm{P}) \mathrm{H}$ oxidase e consequentemente influência na ritmicidade da secreção de insulina estimulada pela glicose.

Dentro deste contexto verificamos que a melatonina inibe a secreção de insulina estimulada pela glicose, sem alterar a oxidação da glicose-[U- $\left.{ }^{14} \mathrm{C}\right]$, contudo, modula a expressão da PKA (PICINATO et al., 2002b). Em células $\beta$ primárias (KEMP; UBEDA; HABENER, 2002; PESCHKE et al., 2002) observaram que a melatonina inibe o processo de secreção de insulina devido a redução da concentração plasmática de $\mathrm{AMP}_{\mathrm{C}}$, com subsequente diminuição da ativação da PKA. Considerando a importância da amplificação da via de sinalização do AMPc/PKA na secreção de insulina estimulada pela glicose (PETER THAMS et al., 2005), as ilhotas isoladas de ratos intactos no ZT-18 estão susceptíveis à modulação da melatonina, com uma possível inibição da secreção de insulina pelo referido indol (KEMP; UBEDA; HABENER, 2002; PICINATO et al., 2002b; STUMPF; BAZWINSKY; PESCHKE, 2009) (Figura 6b), ao contrario do observado no ZT6. 
A.

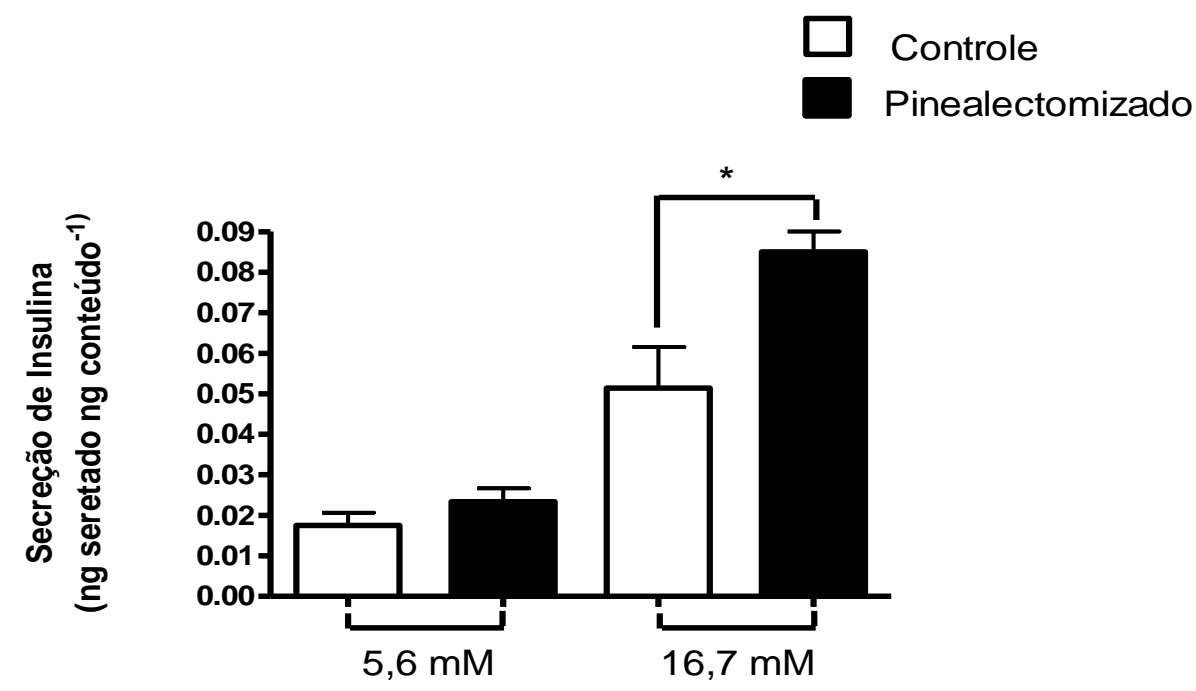

B.

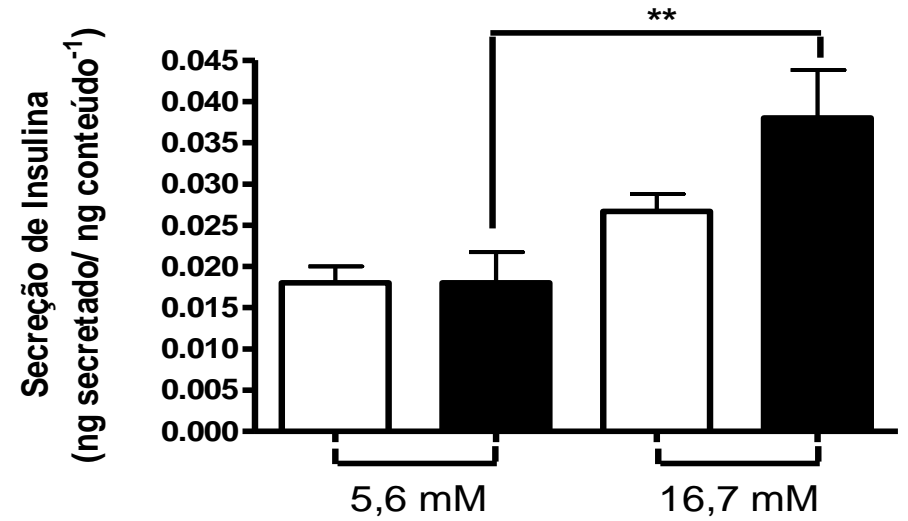

Figura 6 - Análise da secreção estática de insulina dos animais controle e pinealectomizados Ilhotas pancreáticas isoladas foram incubadas por 60 minutos em 5,6 mM e 16, mM glicose, (A) ZT-6 e (B) ZT-18. Os resultados são expressos em média \pm erro padrão da média $(n=5)$. one-way ANOVA, Tukey's multiple comparison test. ${ }^{*} \mathrm{p}<0,05,{ }^{*} \mathrm{p}<0,01$. 


\subsection{Avaliações da expressão protéica das subunidades da NAD(P)H oxidase no ZT-6 e ZT- 18}

A melatonina inibe a atividade e expressão da NAD(P)H oxidase (ZHOU et al., 2008), de maneira semelhante, em dados não publicados do nosso laboratório, observamos que a melatonina inibe a expressão gênica da subunidade p22 $2^{\text {phox }}$ e subsequente redução do conteúdo intracelular de superóxido nas ilhotas isoladas. Considerando a participação da NAD(P)H oxidase nos resultados apresentados, verificou-se que a ausência de melatonina circulante não modifica a expressão de suas subunidades.

Analisamos no ZT-6, a expressão da subunidade citosólica responsável pela translocação das demais subunidades para a membrana plasmática, a p47 $7^{\text {phox }}$, e da subunidade de membrana responsável pela produção de superóxido, gp91 ${ }^{\text {phox }}$ (BABIOR, 1999). No entanto, curiosamente, não observamos alteração na expressão das subunidades induzida pela ausência de melatonina (Figura $7 \mathrm{a}$ e b).

Avaliamos no ZT-18, a expressão das subunidades gp91 ${ }^{\text {phox }}$ e $\mathrm{p} 22^{\text {phox }}$, sendo a última responsável pela ancoragem das subunidades citosólicas (BABIOR, 1999). No entanto, também não verificamos alteração na expressão das subunidades induzida pela pinealectomia (Figura 7c e d).

A pinealectomia não alterou a expressão das subunidades da NAD(P)H oxidase, embora, os resultados apresentados anteriormente demonstram uma possível participação do complexo enzimático na funcionalidade das células $\beta$ pancreáticas. 
A.

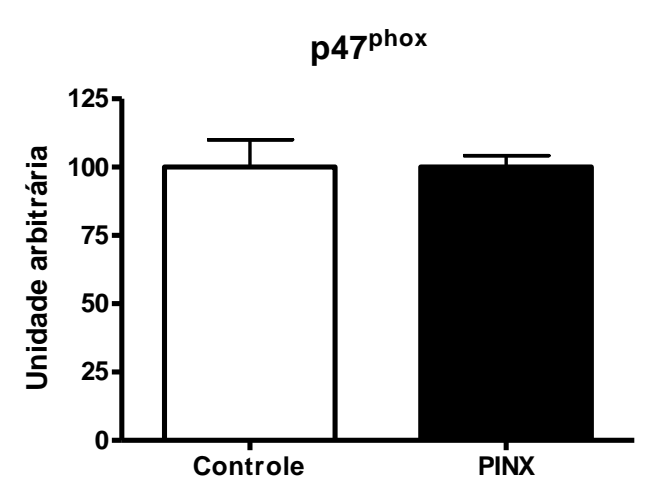

C.

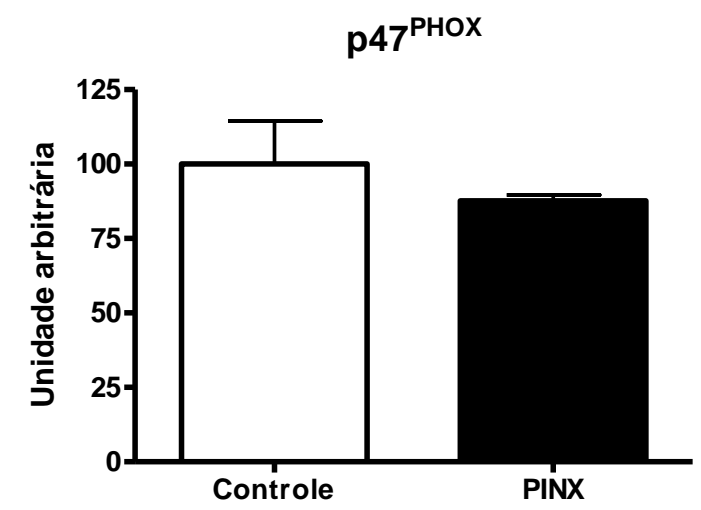

B.

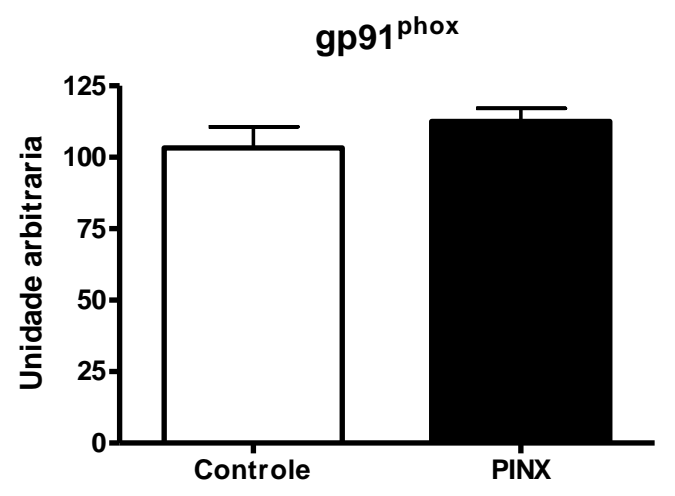

D.

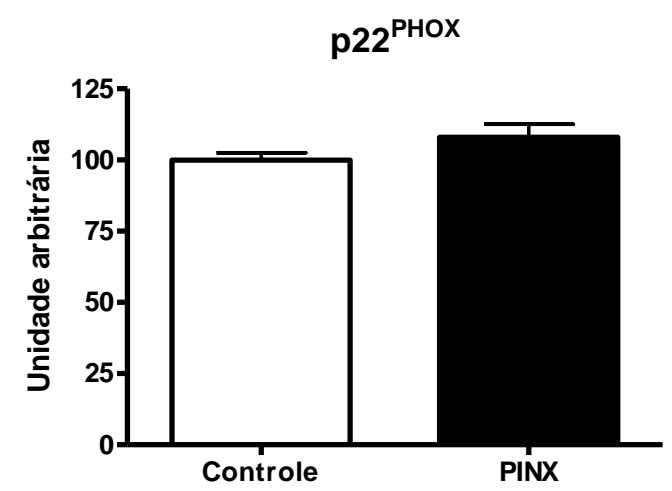

Figura 7 - Expressão protéica das subunidades da NAD(P)H oxidase nos animais controle e pinealectomizados Avaliação da expressão protéica em Ilhotas pancreáticas isoladas, p47 ${ }^{\text {PHOX }}$ (A) e gp91 ${ }^{\text {PHOX }}$ (B) no ZT-6 e gp91 ${ }^{\mathrm{PHOX}}(\mathrm{C})$ e p22 ${ }^{\mathrm{PHOX}}$ (D) no ZT-18. Os resultados são expressos como unidade arbitrária, dados obtidos a partir da densitometria obtidas em três experimentos. O conteúdo protéico foi corrigido pela proteína $\alpha$ tubulina. 


\section{CONCLUSÃO}

Considerando a modulação da funcionalidade das células $\beta$ pancreáticas pela $\mathrm{NAD}(\mathrm{P}) \mathrm{H}$ oxidase e a influência da pinealectomia na atividade dessa enzima, pode-se concluir que as alterações observadas na resposta secretória, metabólica e EROs são promovidas pela pinealectomia. Portanto, podemos supor que a glândula pineal, através da produção de melatonina, poderia modular processos fisiológicos relacionados à produção de EROs e consequentemente a secreção de insulina nas células $\beta$ pancreáticas. 


\section{REFERÊNCIAS $^{2}$}

ALONSO, M.; COLLADO, P. S.; GONZALEZ-GALLEGO, J. Melatonin inhibits the expression of the inducible isoform of nitric oxide synthase and nuclear factor kappa $B$ activation in rat skeletal muscle. J. Pineal Res., v. 41, n. 1, p. 8-14, 2006.

BABIOR, B. M. NADPH oxidase: an update. Blood, v. 93, n. 5, p. 1464-1476, 1999.

BABIOR, B. M. The leukocyte NADPH oxidase. Isr. Med. Assoc. J., v. 4, n. 11, p. 10231024, 2002.

BACH, A. G. et al. Melatonin stimulates inositol-1,4,5-trisphosphate and Ca2+ release from INS1 insulinoma cells. J. Pineal Res., v. 39, n. 3, p. 316-323, 2005.

BAHR, I. et al. Melatonin stimulates glucagon secretion in vitro and in vivo. J. Pineal Res., v. 50, n. 3, p. 336-344, 2011.

BAILEY, C. J.; ATKINS, T. W.; MATTY, A. J. Melatonin inhibition of insulin secretion in the rat and mouse. Horm. Res., v. 5, n. 1, p. 21-28, 1974.

BARRETT, P. et al. Regulation of the Mel 1a melatonin receptor mRNA and protein levels in the ovine pars tuberalis: evidence for a cyclic adenosine 3',5'-monophosphate-independent Mel 1a receptor coupling and an autoregulatory mechanism of expression. Mol. Endocrinol., v. 10, n. 7, p. 892-902, 1996.

BAYDAS, G. et al. Daily rhythm of glutathione peroxidase activity, lipid peroxidation and glutathione levels in tissues of pinealectomized rats. Neurosci. Lett., v. 323, n. 3, p. 195-198, 2002.

BEDARD, K.; KRAUSE, K. H. The NOX family of ROS-generating NADPH oxidases: physiology and pathophysiology. Physiol. Rev., v. 87, n. 1, p. 245-313, 2007.

BEDARD, K.; LARDY, B.; KRAUSE, K. H. NOX family NADPH oxidases: not just in mammals. Biochimie., v. 89, n. 9, p. 1107-1112, 2007.

BENSON, B.; MILLER, C. W.; SORRENTINO, S., JR. Effects of blinding on blood glucose and serum insulin-like activity in rats. Tex. Rep. Biol. Med., v. 29, n. 4, p. 513-525, 1971.

BINDOKAS, V. P. et al. Visualizing superoxide production in normal and diabetic rats islets ol Langerhans. J. Biol. Chem., v. 278, n. 11, p. 9796-9801, 2003

BOKOCH, G. M.; ZHAO, T. Regulation of the phagocyte NADPH oxidase by Rac GTPase. Antioxid. Redox Signal, v. 8, n. 9-10, p. 1533-1548, 2006.

BORGES-SILVA, C. N. et al. Pinealectomy reduces hepatic and muscular glycogen content and attenuates aerobic power adaptability in trained rats. J. Pineal Res., v. 43, n. 1, p. 96-103,

\footnotetext{
${ }^{2}$ De acordo com:

ASSOCIAÇÃO BRASILEIRA DE NORMAS TÉCNICAS. NBR 6023: informação e documentação: referências: elaboração. Rio de Janeiro, 2002.
} 
2007.

BULTEAU, A. L. Redox-dependent modulation of aconitase activity in intact mitochondria. Biochemistry, v. 42, n. 50, p. 14846-14855, 2003.

BURNS, J. K. Serum sodium and potassium and blood glucose levels in cynamolgus monkeys after administration of melatonin. J. Physiol., v. 232, n. 2, p. 84P-85P, 1973.

CARRETERO, M. et al. Long-term melatonin administration protects brain mitochondria from aging. J. Pineal Res., v. 47, n. 2, p. 192-200, 2009.

CHAMPNEY, T. H. et al. Alterations in components of the pineal melatonin synthetic pathway by acute insulin stress in the rat and Syrian hamster. Brain Res., v. 338, n. 1, p. 25$32,1985$.

CIPOLLA-NETO, J. et al. The role of the retrochiasmatic area in the control of pineal metabolism. Neuroendocrinology, v. 69, n. 2, p. 97-104, 1999.

CIPOLlA-NETO, J.; AFECHE, S.C. Glândula Pineal. In: AIRES, M.M (Ed). Fisiologia. 3. ed. Rio de Janeiro: Guanabara-Koogan, 2007. p. 980-990

CONTRERAS-ALCANTARA, S.; BABA, K.; TOSINI, G. Removal of melatonin receptor type 1 induces insulin resistance in the mouse. Obesity (Silver Spring), v. 18, n. 9, p. 1861$1863,2010$.

CSABA, G.; NAGY, S. U. The regulatory role of the pineal gland on the thyroid gland, adrenal medulla and islets of Langerhans. Acta Biol. Med.Ger., v. 31, n. 4, p. 617-619, 1973.

CSERNUS, V. J. et al. Dynamic insulin secretion from perifused rat pancreatic islets. Cell Mol. Life Sci., v. 54, n. 7, p. 733-743, 1998.

DElATTRE, E.; CIPOLlA-NETO, J.; BOSCHERO, A. C. Diurnal variations in insulin secretion and $\mathrm{K}+$ permeability in isolated rat islets. Clin. Exp. Pharmacol. Physiol., v. 26, n. 7, p. 505-510, 1999.

DHAR, M. et al. Effect of melatonin on glucose tolerance and blood glucose circadian rhythm in rabbits. Indian J. Physiol. Pharmacol., v. 27, n. 2, p. 109-117, 1983.

DIAZ, B.; BLAZQUEZ, E. Effect of pinealectomy on plasma glucose, insulin and glucagon levels in the rat. Horm. Metab. Res., v. 18, n. 4, p. 225-229, 1986.

DUBOCOVICH, M. L. Melatonin receptors: are there multiple subtypes? Trends Pharmacol. Sci., v. 16, n. 2, p. 50-56, 1995.

EBELT, H. et al. Influence of melatonin on free radical-induced changes in rat pancreatic beta-cells in vitro. J. Pineal Res., v. 28, n. 2, p. 65-72, 2000.

ELLSON, C. D. et al. Neutrophils from p40phox-/- mice exhibit severe defects in NADPH oxidase regulation and oxidant-dependent bacterial killing. J. Exp. Med., v. 203, n. 8, p. 
1927-1937, 2006.

FABIS, M.; PRUSZYNSKA, E.; MACKOWIAK, P. In vivo and in situ action of melatonin on insulin secretion and some metabolic implications in the rat. Pancreas, v. 25, n. 2, p. 166$169,2002$.

FISHER, A. B. Redox signaling across cell membranes. Antioxid. Redox Signal, v. 11, n. 6, p. 1349-1356, 2009.

FONTAYNE, A. et al. Phosphorylation of p47phox sites by PKC alpha, beta II, delta, and zeta: effect on binding to p22phox and on NADPH oxidase activation. Biochemistry, v. 41, n. 24 , p. $7743-7750,2002$.

GEMBAL, M.; GILON, P.; HENQUIN, J. C. Evidence that glucose can control insulin release independently from its action on ATP-sensitive $\mathrm{K}+$ channels in mouse B cells. J. Clin. Invest., v. 89, n. 4, p. 1288-1295, 1992.

GILON, P.; HENQUIN, J. C. Mechanisms and physiological significance of the cholinergic control of pancreatic beta-cell function. Endocr. Rev., v. 22, n. 5, p. 565-604, 2001.

GORRAY, K. C.; QUAY, W. B. Effects of pinealectomy and of sham-pinealectomy on blood glucose levels in the alloxan-diabetic rat. Horm. Metab. Res., v. 10, n. 5, p. 389-392, 1978.

GORRAY, K. C.; QUAY, W. B.; EWART, R. B. Effects of pinealectomy and pineal incubation medium and sonicates on insulin release by isolated pancreatic islets in vitro. Horm. Metab. Res., v. 11, n. 7, p. 432-436, 1979.

GRACIANO, M. F. et al. NAD(P)H oxidase participates in the palmitate-induced superoxide production and insulin secretion by rat pancreatic islets. J. Cell Physiol., v. 226, n. 4, p. 1110 1117, 2010.

GRIENDLING, K. K. et al. Angiotensin II stimulates NADH and NADPH oxidase activity in cultured vascular smooth muscle cells. Circ. Res., v. 74, n. 6, p. 1141-1148, 1994.

GRIENDLING, K. K.; USHIO-FUKAI, M. Reactive oxygen species as mediators of angiotensin II signaling. Regul. Pept., v. 91, n. 1-3, p. 21-27, 2000.

HABER, E. P. et al. Pleiotropic effects of fatty acids on pancreatic beta-cells. J. Cell Physiol., v. 194, n. 1, p. 1-12, 2003.

HARDELAND, R. Melatonin: signaling mechanisms of a pleiotropic agent. Biofactors, v. 35, n. 2, p. 183-192, 2009.

HEYWORTH, P. G.; CROSS, A. R.; CURNUTTE, J. T. Chronic granulomatous disease. Curr. Opin Immunol., v. 15, n. 5, p. 578-584, 2003.

IMOTO, H. et al. Impaired insulin secretion by diphenyleneiodium associated with perturbation of cytosolic Ca2+ dynamics in pancreatic beta-cells. Endocrinology, v. 149, n. 11, p. 5391-5400, 2008. 
JONES, P. M.; PERSAUD, S. J.; HOWELL, S. L. Ca2(+)-induced insulin secretion from electrically permeabilized islets. Loss of the $\mathrm{Ca} 2(+)$-induced secretory response is accompanied by loss of Ca2(+)-induced protein phosphorylation. Biochem. J., v. 285 ( Pt 3), n., p. 973-978, 1992.

KALSBEEK, A. et al. The hypothalamic clock and its control of glucose homeostasis. Trends Endocrinol. Metab., v. 21, n. 7, p. 402-410.

KEMP, D. M.; UBEDA, M.; HABENER, J. F. Identification and functional characterization of melatonin Mel 1a receptors in pancreatic beta cells: potential role in incretin-mediated cell function by sensitization of cAMP signaling. Mol. Cell Endocrinol., v. 191, n. 2, p. 157-166, 2002.

KRAUSE, K. H. Tissue distribution and putative physiological function of NOX family NADPH oxidases. Jpn. J. Infect Dis., v. 57, n. 5, p. S28-29, 2004.

KUCUKAKIN, B.; GOGENUR, I.; ROSENBERG, J. [Melatonin against surgical stress]. Ugeskr Laeger, v. 169, n. 14, p. 1306-1308, 2007.

LACY, P. E., KOSTIANOVSKY, M. Method for the isolation of intact islets of langerhans from the rat pancreas. Diabetes, v. 16, n. 1, p. 35-39, 1967

LA FLEUR, S. E. et al. Role for the pineal and melatonin in glucose homeostasis: pinealectomy increases night-time glucose concentrations. J. Neuroendocrinol, v. 13, n. 12, p. 1025-1032, 2001.

LENZEN, S. Oxidative stress: the vulnerable beta-cell. Biochem. Soc. Trans., v. 36, n. Pt 3, p. 343-347, 2008.

LENZEN, S.; DRINKGERN, J.; TIEDGE, M. Low antioxidant enzyme gene expression in pancreatic islets compared with various other mouse tissues. Free Radic. Biol. Med., v. 20, n. 3, p. 463-466, 1996.

LIMA, F. B. et al. Pinealectomy causes glucose intolerance and decreases adipose cell responsiveness to insulin in rats. Am. J. Physiol., v. 275, n. 6 Pt 1, p. E934-941, 1998.

LIMA, L. M. B. de.; REIS, L. C. dos.; LIMA, M. A. de Influence of The Pineal Gland on The Physiology, Morphometry and Morphology of Pancreatic Islets in Rats. Rev. Brasil. Biol., v. 61, n. 2, p. 333-340, 2001

LIND, C. et al. Studies on the mechanism of oxidative modification of human glyceraldehyde-3-phosphate dehydrogenase by glutathione: catalysis by glutaredoxin. Biochem. Biophys. Res. Commun., v. 247, n. 2, p. 481-486, 1998.

LIU, F.; NG, T. B. Effect of pineal indoles on activities of the antioxidant defense enzymes superoxide dismutase, catalase, and glutathione reductase, and levels of reduced and oxidized glutathione in rat tissues. Biochem. Cell Biol., v. 78, n. 4, p. 447-453, 2000. 
LOPEZ, A. et al. Melatonin protects the mitochondria from oxidative damage reducing oxygen consumption, membrane potential, and superoxide anion production. J. Pineal Res., v. 46, n. 2, p. 188-198, 2009.

MARCHEVA, B. et al. Disruption of the clock components CLOCK and BMAL1 leads to hypoinsulinaemia and diabetes. Nature, v. 466, n. 7306, p. 627-631, 2010.

MATSCHINSKY, F. M. Banting Lecture 1995. A lesson in metabolic regulation inspired by the glucokinase glucose sensor paradigm. Diabetes, v. 45, n. 2, p. 223-241, 1996.

MEIER, B. et al. Identification of a superoxide-generating NADPH oxidase system in human fibroblasts. Biochem. J., v. 275 ( Pt 1), n., p. 241-245, 1991.

MOORE, P. C. et al. Evidence against the involvement of oxidative stress in fatty acid inhibition of insulin secretion. Diabetes, v. 53, n. 10, p. 2610-2616, 2004.

MORGAN, D. et al. Glucose, palmitate and pro-inflammatory cytokines modulate production and activity of a phagocyte-like NADPH oxidase in rat pancreatic islets and a clonal beta cell line. Diabetologia, v. 50, n. 2, p. 359-369, 2007.

MORGAN, D. et al. Association of NAD(P)H oxidase with glucose-induced insulin secretion by pancreatic beta-cells. Endocrinology, v. 150, n. 5, p. 2197-2201, 2009.

MORGAN, P. J. et al. Melatonin receptors couple through a cholera toxin-sensitive mechanism to inhibit cyclic AMP in the ovine pituitary. J. Neuroendocrinol., v. 7, n. 5, p. 361-369, 1995.

MORGAN, P. J. et al. Melatonin receptors: localization, molecular pharmacology and physiological significance. Neurochem. Int., v. 24, n. 2, p. 101-146, 1994.

MUHLBAUER, E.; PESCHKE, E. Evidence for the expression of both the MT1- and in addition, the MT2-melatonin receptor, in the rat pancreas, islet and beta-cell. J. Pineal Res., v. 42, n. 1, p. 105-106, 2007.

MUHLBAUER, E. et al. Indication of circadian oscillations in the rat pancreas. FEBS Lett., v. 564, n. 1-2, p. 91-96, 2004.

MURLIDHAR et al. Effect of pinealectomy on daily rhythm of blood glucose in rabbits. Indian. J. Exp. Biol., v. 29, n. 3, p. 278-279, 1991.

NANU-IONESCU, L.; IONESCU, V. [The pineal gland and insulin metabolism. I. The plasma level of total insulin activity and of "free" and "bound" insulin in experimental apinealism]. Stud. Cercet. Endocrinol., v. 20, n. 3, p. 237-243, 1969.

NAUSEEF, W. M. Biological roles for the NOX family NADPH oxidases. J. Biol. Chem., v. 283, n. 25, p. 16961-16965, 2008.

NESHER, R. et al. Beta-cell protein kinases and the dynamics of the insulin response to glucose. Diabetes, v. 51 Suppl 1, n., p. S68-73, 2002. 
NOGUEIRA, T. C. et al. Absence of melatonin induces night-time hepatic insulin resistance and increased gluconeogenesis due to stimulation of nocturnal unfolded protein response. Endocrinology, v. 152, n. 4, p. 1253-1263, 2011.

OLIVEIRA, H. R.; CURI, R.; CARPINELLI, A. R. Glucose induces an acute increase of superoxide dismutase activity in incubated rat pancreatic islets. Am. J. Physiol., v. 276, n. 2 Pt 1, p. C507-510, 1999.

OLIVEIRA, H. R. et al. Pancreatic beta-cells express phagocyte-like NAD(P)H oxidase. Diabetes, v. 52, n. 6, p. 1457-1463, 2003.

OZTURK, G. et al. The effect of melatonin on liver superoxide dismutase activity, serum nitrate and thyroid hormone levels. Jpn. J. Physiol., v. 50, n. 1, p. 149-153, 2000.

PELICIARI-GARCIA, R. A. et al. Insulin temporal sensitivity and its signaling pathway in the rat pineal gland. Life Sci., v. 87, n. 5-6, p. 169-174, 2010.

PESCHKE, E.; BACH, A. G.; MUHLBAUER, E. Parallel signaling pathways of melatonin in the pancreatic beta-cell. J. Pineal Res., v. 40, n. 2, p. 184-191, 2006.

PESCHKE, E. et al. Evidence for a melatonin receptor within pancreatic islets of neonate rats: functional, autoradiographic, and molecular investigations. J. Pineal Res., v. 28, n. 3, p. 156$164,2000$.

PESCHKE, E. et al. Receptor (MT(1)) mediated influence of melatonin on cAMP concentration and insulin secretion of rat insulinoma cells INS-1. J. Pineal Res., v. 33, n. 2, p. 63-71, 2002.

PESCHKE, E.; PESCHKE, D. Evidence for a circadian rhythm of insulin release from perifused rat pancreatic islets. Diabetologia, v. 41, n. 9, p. 1085-1092, 1998.

PESCHKE, E. et al. Influence of melatonin and serotonin on glucose-stimulated insulin release from perifused rat pancreatic islets in vitro. J. Pineal Res., v. 23, n. 3, p. 156-163, 1997.

PICINATO, M. C. et al. Daily rhythm of glucose-induced insulin secretion by isolated islets from intact and pinealectomized rat. J. Pineal Res., v. 33, n. 3, p. 172-177, 2002a.

PICINATO, M. C. et al. Melatonin inhibits insulin secretion and decreases PKA levels without interfering with glucose metabolism in rat pancreatic islets. J. Pineal Res., v. 33, n. 3, p. 156-160, 2002b.

PICINATO, M. C. et al. Activation of insulin and IGF-1 signaling pathways by melatonin through MT1 receptor in isolated rat pancreatic islets. J. Pineal Res., v. 44, n. 1, p. 88-94, 2008.

QUAY, W. B.; GORRAY, K. C. Pineal effects on metabolism and glucose homeostasis: evidence for lines of humoral mediation of pineal influences on tumor growth. J. Neural. 
Transm, v. 47, n. 2, p. 107-120, 1980.

RAMRACHEYA, R. D. et al. Function and expression of melatonin receptors on human pancreatic islets. J. Pineal Res., v. 44, n. 3, p. 273-279, 2008.

RASMUSSEN, D. D. et al. Daily melatonin administration at middle age suppresses male rat visceral fat, plasma leptin, and plasma insulin to youthful levels. Endocrinology, v. 140, n. 2, p. 1009-1012, 1999.

RASMUSSEN, D. D. et al. Aging-dependent changes in the effect of daily melatonin supplementation on rat metabolic and behavioral responses. J. Pineal Res., v. 31, n. 1, p. 8994, 2001.

REITER, R. J. Antioxidant actions of melatonin. Adv. Pharmacol., v. 38, n., p. 103-117, 1997.

REITER, R. J. et al. Melatonin in relation to the "strong" and "weak" versions of the free radical theory of aging. Adv. Med. Sci., v. 53, n. 2, p. 119-129, 2008.

REITER, R. J. et al. Actions of melatonin in the reduction of oxidative stress. A review. J. Biomed. Sci., v. 7, n. 6, p. 444-458, 2000a.

REITER, R. J. et al. Pharmacology and physiology of melatonin in the reduction of oxidative stress in vivo. Biol. Signals Recept., v. 9, n. 3-4, p. 160-171, 2000 b.

RODRIGUEZ, C. et al. Regulation of antioxidant enzymes: a significant role for melatonin. $\mathbf{J}$. Pineal Res., v. 36, n. 1, p. 1-9, 2004.

RODRIGUEZ, V. et al. Effect of pinealectomy on liver insulin and glucagon receptor concentrations in the rat. J. Pineal Res., v. 6, n. 1, p. 77-88, 1989.

SAHNA, E. et al. Efficacy of melatonin as protectant against oxidative stress and structural changes in liver tissue in pinealectomized rats. Acta Histochem., v. 106, n. 5, p. 331-336, 2004.

SANI, M. et al. Catalase activity and rhythmic patterns in mouse brain, kidney and liver.

Comp. Biochem. Physiol. B. Biochem. Mol. Biol., v. 145, n. 3-4, p. 331-337, 2006.

SLOMINSKI, A. et al. Melatonin in the skin: synthesis, metabolism and functions. Trends Endocrinol. Metab., v. 19, n. 1, p. 17-24, 2008.

SMIRNOV, A. N. Nuclear melatonin receptors. Biochemistry (Mosc), v. 66, n. 1, p. 19-26, 2001.

STUMPF, I.; BAZWINSKY, I.; PESCHKE, E. Modulation of the cGMP signaling pathway by melatonin in pancreatic beta-cells. J. Pineal Res., v. 46, n. 2, p. 140-147, 2009.

STUMPF, I.; MUHLBAUER, E.; PESCHKE, E. Involvement of the cGMP pathway in mediating the insulin-inhibitory effect of melatonin in pancreatic beta-cells. J. Pineal Res., v. 
45, n. 3, p. 318-327, 2008.

TANG, C. et al. Evidence for a role of superoxide generation in glucose-induced beta-cell dysfunction in vivo. Diabetes, v. 56, n. 11, p. 2722-2731, 2007.

THAMS, P.; ANWAR, M. R.; CAPITO, K. Glucose triggers protein kinase A-dependent insulin secretion in mouse pancreatic islets through activation of the K+ATP channeldependent pathway. Eur. J. Endocrinol., v. 152, n. 4, p. 671-677, 2005.

UCHIZONO, Y. et al. Expression of isoforms of NADPH oxidase components in rat pancreatic islets. Life Sci., v. 80, n. 2, p. 133-139, 2006.

WENZEL, P. et al. First evidence for a crosstalk between mitochondrial and NADPH oxidase-derived reactive oxygen species in nitroglycerin-triggered vascular dysfunction. Antioxid Redox Signal, v. 10, n. 8, p. 1435-1447, 2008.

WOSNIAK, J., JR. et al. Cross-talk between mitochondria and NADPH oxidase: effects of mild mitochondrial dysfunction on angiotensin II-mediated increase in Nox isoform expression and activity in vascular smooth muscle cells. Antioxid Redox Signal, v. 11, n. 6, p. 1265-1278, 2009.

ZHAO, H. et al., Superoxide reacts with hydroethidine but forms a fluorescent product that is distinctly diferent from ethidium: potential implications in intracellular fluorescence detection of superoxide. Free Radic. Biol. Med., v. 34, n. 11, p. 1359-1368, 2003

ZHOU, J. et al. Melatonin impairs NADPH oxidase assembly and decreases superoxide anion production in microglia exposed to amyloid-beta1-42. J. Pineal Res., v. 45, n. 2, p. 157-165, 2008 . 